\title{
¿Separating the Impact of Individual Land Surface Properties on the Terrestrial Surface Energy Budget in both the Coupled and Uncoupled Land-Atmosphere System $\mathscr{O}$
}

\author{
MARYSA M. LAGUË \\ Department of Atmospheric Sciences, University of Washington, Seattle, Washington \\ GORDON B. BONAN \\ National Center for Atmospheric Research, Boulder, Colorado \\ ABIGAIL L. S. SWANN \\ Department of Atmospheric Sciences, and Department of Biology, University of Washington, Seattle, Washington
}

(Manuscript received 27 November 2018, in final form 7 June 2019)

\begin{abstract}
Changes in the land surface can drive large responses in the atmosphere on local, regional, and global scales. Surface properties control the partitioning of energy within the surface energy budget to fluxes of shortwave and longwave radiation, sensible and latent heat, and ground heat storage. Changes in surface energy fluxes can impact the atmosphere across scales through changes in temperature, cloud cover, and large-scale atmospheric circulation. We test the sensitivity of the atmosphere to global changes in three land surface properties: albedo, evaporative resistance, and surface roughness. We show the impact of changing these surface properties differs drastically between simulations run with an offline land model, compared to coupled land-atmosphere simulations that allow for atmospheric feedbacks associated with land-atmosphere coupling. Atmospheric feedbacks play a critical role in defining the temperature response to changes in albedo and evaporative resistance, particularly in the extratropics. More than $50 \%$ of the surface temperature response to changing albedo comes from atmospheric feedbacks in over $80 \%$ of land areas. In some regions, cloud feedbacks in response to increased evaporative resistance result in nearly $1 \mathrm{~K}$ of additional surface warming. In contrast, the magnitude of surface temperature responses to changes in vegetation height are comparable between offline and coupled simulations. We improve our fundamental understanding of how and why changes in vegetation cover drive responses in the atmosphere, and develop understanding of the role of individual land surface properties in controlling climate across spatial scales — critical to understanding the effects of land-use change on Earth's climate.
\end{abstract}

\section{Introduction}

While it is intuitive to think about how climate impacts the land surface, here we focus on how changes in the land surface influence the climate system. In particular, we focus on the effects of changing land surface

Denotes content that is immediately available upon publication as open access.

Supplemental information related to this paper is available at the Journals Online website: https://doi.org/10.1175/JCLI-D-180812.s1.

Corresponding author: Marysa M. Laguë, mlague@uw.edu properties associated with vegetation change. The effects on climate of changing vegetation vary depending on the location of the vegetation change.

For example, tropical forests have high rates of transpiration, and thus high rates of evaporative cooling; tropical deforestation reduces this evaporative cooling effect, leading to warming at the surface (Bonan 2008b). Increasing tree cover in the midlatitudes has been shown to alter climate locally by warming and reducing cloud cover (Swann et al. 2012; Laguë and Swann 2016). Changes in vegetation at high latitudes can modify surface temperatures through both surface albedo and atmospheric water vapor changes (Bonan 2008b; Swann et al. 2010). The effects of historical land-use and landcover change have been shown to impact near-surface 
air temperatures and energy fluxes (Pitman et al. 2009; de Noblet-Ducoudré et al. 2012), while future land use has been proposed as a potential method of mitigating anthropogenic climate change (Canadell and Raupach 2008). In addition to directly influencing surface fluxes and temperature, interactions between vegetation change and the atmosphere can drive atmospheric feedbacks and global-scale teleconnections, which further influence surface climate, both locally and remotely (Bonan 2008b; Swann et al. 2012; Laguë and Swann 2016; Kooperman et al. 2018).

Vegetation change has been observed to drive changes in surface energy fluxes across a range of biomes (Lee et al. 2011). In addition to observational studies, much of our understanding of land-atmosphere coupling and vegetation-climate feedbacks comes from models of Earth's land-atmosphere-ocean-sea ice system. Land surface models represent the biogeophysical coupling between the land and atmosphere through fluxes of momentum, energy, and water, which are in turn modulated by the land surface albedo, rates of evapotranspiration, and aerodynamic surface roughness. The climate at the land surface is determined both by the background regional climate and by the characteristics of the local land surface; changes in individual land surface properties each have a different impact on surface temperature and energy fluxes. Albedo directly controls the amount of solar energy absorbed by the surface; aerodynamic roughness controls the efficiency of turbulent energy exchange with the atmosphere; and the resistance to evapotranspiration controls how much water can move from the land surface to the atmosphere. Changes in vegetation modify each of these surface properties in different ways, and changes in different properties of the land surface drive changes in the surface energy budget and surface temperatures. Through these changes in energy fluxes, the land can drive changes in the atmosphere, ranging from small local changes in air temperatures or cloud cover to large, global-scale changes in circulation (Devaraju et al. 2018).

Surface energy fluxes are the complex outcome of biogeophysical processes at the land surface, with changes in any individual surface property having a different effect on climate. In modern Earth system models, it is often difficult to individually perturb a single land surface property. In a model such as the Community Land Model (CLM; Lawrence et al. 2018), surface albedo is the complex result of leaf and stem reflectance and transmittance, the orientation of leaves, the amount of leaf and stem material, interception of snow in the canopy, soil color, soil moisture, and snow cover. Evaporation is calculated from stomatal conductance for transpiration, a conductance for soil evaporation, and evaporation of intercepted water held externally on foliage. Stomatal conductance itself depends on photosynthetic rates as determined by the photosynthetic capacity of the canopy as modified by light absorption, temperature, vapor pressure deficit, soil moisture availability, and atmospheric $\mathrm{CO}_{2}$ concentration. Because of these complex relationships, many seemingly simple properties of a land surface model, such as albedo, are actual emergent properties of the model. As such, it is difficult to directly prescribe a change in a specific surface property such as albedo or evaporative resistance, or anticipate how a change in vegetation type may actually influence these surface properties. Davin and de Noblet-Ducoudré (2010) isolated the individual effects of albedo, evaporative resistance, and surface roughness when comparing the climate effects of forests versus grasslands using the Organizing Carbon and Hydrology in Dynamic Ecosystems (ORCHIDEE) land model, but such a modeling protocol is uncommon. Alternatively, using climate models with imposed vegetation change, or a mix of linearized surface energy budget equations and flux tower observations, the relative contribution of different surface fluxes to changes in surface temperatures can be estimated (Lee et al. 2011; Boisier et al. 2012).

The effects of human-induced land use and land cover change can vary largely between different landatmosphere models, as shown by the "Land Use and Climate, Identification of Robust Impacts" (LUCID) experiments (Pitman et al. 2009; De Noblet-Ducoudré et al. 2012). These differences come in large part from the different ways various models represent complex land surface properties. Here, we focus explicitly on testing the sensitivity of the climate system to three land surface properties in a single land-atmosphere model.

Modifying surface energy fluxes through vegetation change has a direct impact on surface climate. Independent of interactions with the atmosphere, repartitioning surface energy fluxes on the land surface can modify surface temperatures and water availability. Land-atmosphere coupling with the near-surface atmosphere further modifies the effect of a change in some land surface property on surface temperatures and energy fluxes. For example, Vargas Zeppetello et al. (2019) discuss the coupling between surface temperatures, lower-atmospheric temperatures, and downwelling longwave radiation reaching the land surface, while Dirmeyer (2001) identify regions with strong coupling between the land surface state and lower-atmospheric temperatures, humidity, and even precipitation. 
In addition to local, near-surface land-atmosphere coupling changes in response to changes in the land surface, larger-scale changes in the atmosphere can also occur in response to land surface changes, which can then feed back on surface climate, both locally and remotely. For example, modifying forest cover in the midlatitudes can alter midlatitude cloud cover, which in turn modifies the amount of sunlight reaching the land surface (Laguë and Swann 2016). Vegetation can also modify local precipitation (Kooperman et al. 2018) or remote precipitation by driving changes in large-scale circulation (Swann et al. 2012). These large-scale atmospheric feedbacks to vegetation change can result in remote climate and vegetation responses in regions far removed from the initial vegetation change, as a result of changes in large-scale atmospheric circulation (Swann et al. 2012; Garcia et al. 2016; Laguë and Swann 2016; Swann et al. 2018). Analysis of the climate impact of changes in vegetation that do not allow for atmospheric feedbacks, such as simulations of changes in vegetation forced with noninteractive data atmospheres (e.g., land models forced with reanalysis), captures the direct surface climate response but is unable to capture any of the climate response to vegetation change resulting from atmospheric feedbacks.

Changes in vegetation have been shown to drive substantial atmospheric responses in many modern ESMs (Gibbard et al. 2005; Bala et al. 2007; Davin and de Noblet-Ducoudré 2010; Chen et al. 2012; Medvigy et al. 2013; Devaraju et al. 2015; Badger and Dirmeyer 2015; Swann et al. 2012; Laguë and Swann 2016). However, as mentioned above, changing vegetation type in a modern land model encompasses many simultaneous changes to multiple land surface properties; several studies using early coupled global climate models demonstrated the ability of changes in individual surface properties to influence global climate, including albedo (Charney et al. 1975; Charney 1975; Charney et al. 1977), roughness (Sud et al. 1988), and land evaporation (Shukla and Mintz 1982).

In this study, we introduce an idealized land model, the Simple Land Interface Model (SLIM), which we couple to a modern Earth system model. We use this idealized land model to examine the effects of specified changes in vegetation albedo, evaporative resistance, and surface roughness in uncoupled land-only and in coupled landatmosphere simulations. These simulations examine climate sensitivities to specific land surface processes, identify different regional climate responses, quantify the impact of atmospheric feedbacks from land surface changes, and provide a quantitative evaluation of how large a surface perturbation is required to achieve a desired change in surface temperature.

\section{Methods}

\section{a. Experimental design}

To modify a single land surface property, while holding all other properties fixed, we wrote a very simple land surface model (see section 2b), which can be coupled to the Community Earth System Model (CESM; Hurrell et al. 2013). This simple land model replaces the Community Land Model, version 5 (CLM5; Lawrence et al. 2018), within CESM. Simulations are run coupled to the Community Atmosphere Model, version 5 (CAM5), or forced by an atmospheric dataset; a slabocean model (SOM) (Neale et al. 2012); and the Los Alamos Sea Ice Model for interactive sea ice (CICE5) (Hunke et al. 2013; Bailey et al. 2018). The slab ocean assumes ocean circulation does not change throughout the simulation (monthly heat fluxes are prescribed for each ocean grid cell, representing horizontal and vertical energy transport within the ocean), but allows sea surface temperatures (SSTs), and thus energy exchange with the atmosphere, to adjust to forcings from the atmosphere. SOMs allow atmospheric signals to propagate farther than fixed SST models by allowing ocean temperatures to respond to changes in energy fluxes from the atmosphere, but are much less computationally expensive than fully dynamic ocean models and do not allow for climate signals driven by variability in ocean circulation. As such, the SOM provides a good compromise for studying the impacts of changes in the land surface on atmospheric circulation. The role of oceans in propagating land surface change impacts on global climate has been previously demonstrated (e.g., Bonan et al. 1992; Davin and de Noblet-Ducoudré 2010; Swann et al. 2012); here we capture some of that response by allowing sea surface temperatures and sea ice to change, but do not capture any response relating to changes in ocean circulation or heat capacity.

In each experiment, we modify the value of a single surface property while holding the rest of the surface properties fixed. For each surface property, we run two sets of simulations: one where the land model is forced with a data atmosphere ("offline") and one running fully coupled to CAM5 (Fig. 1). Land models are frequently run offline (i.e., not coupled with an interactive atmosphere); here, we are interested in identifying how imposing the same changes on the land surface model both offline and coupled to an interactive atmosphere impact the resulting surface energy fluxes and temperatures in response to the change in the land surface. Other delineations of the land-atmosphere boundary, such as allowing the land to interact with a boundary layer but not a larger-scale atmosphere, would result in a different interpretation of the role of atmospheric coupling. 


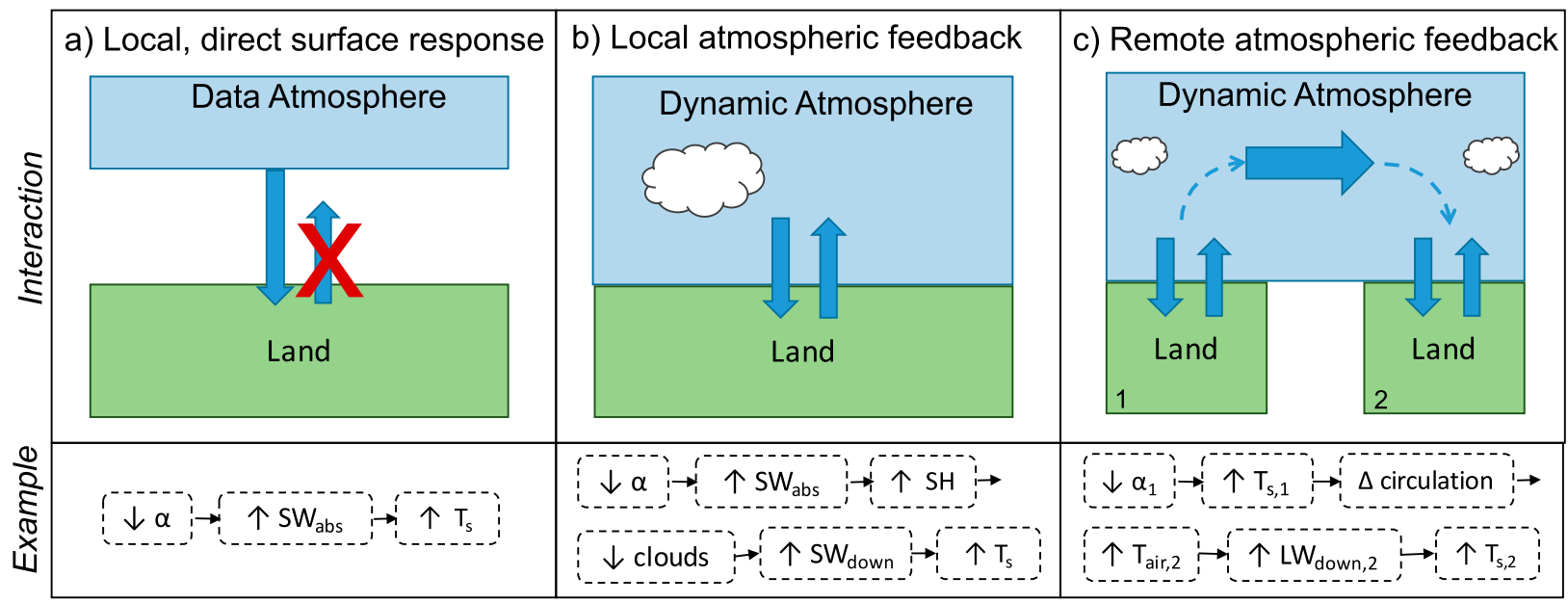

FIG. 1. Three types of land atmosphere interactions: (a) the direct, local response of the surface to the atmosphere (with no feedbacks); (b) local atmospheric feedbacks, where changes in the atmosphere above a modified land surface occur because of the modified land surface below that atmospheric column; and (c) remote atmospheric feedbacks, where a change in land at location 1 drives a large-scale atmospheric response that can in turn impact the land at location 2. Examples of each feedback consider the impact of a change in albedo $\alpha$ on absorbed shortwave energy $\mathrm{SW}_{\mathrm{abs}}$, sensible heat flux SH, cloud cover, downward shortwave energy at the surface $\mathrm{SW}_{\mathrm{down}}, \mathrm{downward}$ longwave energy at the surface $\mathrm{LW}_{\text {down }}$, and surface temperature $T_{s}$

In the offline simulations, we use atmospheric forcing data generated by a control simulation of CAM5 running coupled to the simple land model with the following surface property values over all nonglaciated land regions: snow-free albedo $=0.2$, evaporative resistance $=$ $100 \mathrm{~s} \mathrm{~m}^{-1}$, and vegetation height $=0.1 \mathrm{~m}$. These values were chosen as they roughly correspond to a world where all nonglaciated lands are grasslands. The offline simulations are all forced with the same 3-hourly atmospheric forcing data saved from the last 30 years of this coupled simulation (where the first 20 years are discarded to allow the model to reach equilibrium). We find the results to be qualitatively similar (i.e., the direction and magnitude of the response of surface temperature and energy fluxes to a change in surface property is the same) when the offline simulations are forced with GSWP3 (Global Soil Wetness Project, phase 3; http:// hydro.iis.u-tokyo.ac.jp/GSWP3/) reanalysis (Compo et al. 2011), which is the standard atmospheric forcing dataset used to evaluate CLM5 in offline simulations (Lawrence et al. 2018).

We perturb the value of each of these surface properties over all nonglaciated (in the present day) land surface (Table 1). For albedo $\alpha$, we use $\alpha=0.1$ (comparable to the albedo of a needleleaf evergreen forest), $\alpha=0.2$ (comparable to the albedo of a grassland), and $\alpha=0.3$ (comparable to the albedo of a desert) (Bonan 2008a), while holding evaporative resistance fixed at $100 \mathrm{~s} \mathrm{~m}^{-1}$ and vegetation height fixed at $0.1 \mathrm{~m}$. For evaporative resistance $r_{s}$, we use $r_{s}=50 \mathrm{~s} \mathrm{~m}^{-1}$ (low resistance, comparable to that of a crop like wheat), $r_{s}=$ $100 \mathrm{~s} \mathrm{~m}^{-1}$, and $r_{s}=200 \mathrm{~s} \mathrm{~m}^{-1}$ [moderately high resistance, comparable to that of a pine forest; see Fig. 17.10 in Bonan (2015)], while holding albedo fixed at 0.2 and vegetation height fixed at $0.1 \mathrm{~m}$. For vegetation height $h_{c}$ (height of canopy) we use $h_{c}=0.1$ (short grassland), 1.0 (tall grass), and $2.0 \mathrm{~m}$ (shrub/short tree) (Bonan 2008a). After approximately $2 \mathrm{~m}$ of vegetation

TABLE 1. The values for each experiment are given, with each column of three values corresponding to a single experiment. Values for albedo $\alpha$ are given in the top row, evaporative resistance $r_{s}\left(\mathrm{~s} \mathrm{~m}^{-1}\right)$ in the middle row, and vegetation height $h_{c}(\mathrm{~m})$ in the bottom row. Columns are grouped into the variable being perturbed; note that the "baseline" simulation of $\alpha=0.2, r_{s}=100$, and $h_{c}=0.1$ appears three times but is actually a single simulation.

\begin{tabular}{|c|c|c|c|c|c|c|c|c|c|}
\hline \multirow{3}{*}{$\frac{\text { Surface value }}{\alpha \text { (unitless) }}$} & \multicolumn{9}{|c|}{ Perturbation variable } \\
\hline & \multicolumn{3}{|c|}{ Albedo } & \multicolumn{3}{|c|}{ Evaporative resistance } & \multicolumn{3}{|c|}{ Vegetation height } \\
\hline & 0.1 & 0.2 & 0.3 & 0.2 & 0.2 & 0.2 & 0.2 & 0.2 & 0.2 \\
\hline$r_{s}\left(\mathrm{~s} \mathrm{~m}^{-1}\right)$ & 100 & 100 & 100 & 30 & 100 & 200 & 100 & 100 & 100 \\
\hline$h_{c}(\mathrm{~m})$ & 0.1 & 0.1 & 0.1 & 0.1 & 0.1 & 0.1 & 0.1 & 1.0 & 2.0 \\
\hline
\end{tabular}


height, the response of surface temperatures and energy fluxes to subsequent increases in vegetation height becomes much shallower; as such, we perform an additional three experiments with $h_{c}=5.0,10.0$, and $20.0 \mathrm{~m}$ to explore the response of surface fluxes to a range of tree heights; these results are presented in the supplement, while here we focus on the 0.1-2.0-m range of vegetation heights.

While the goal of this study was to separate the atmospheric sensitivity to individual surface properties which often change simultaneously as a result of vegetation change, there are situations where real-world vegetation change only modifies one of these properties. An example of this is the stomatal response of vegetation to changes in atmospheric water demand, which would modify evaporative resistance but not albedo or vegetation height. Specific crop cultivars have been developed to modify water use (e.g., Zhang et al. 2005), while growing more reflective plants has been proposed as a type of geoengineering (Caldeira et al. 2013). Also, there are other land surface properties not perturbed here that could impact surface energy fluxes over various time scales, including soil heat capacity, which has been shown to impact the diurnal amplitude of surface temperatures (Cheruy et al. 2017).

Each simulation is run for 50 years; we discard the first 20 years of the simulation to allow for the model to reach equilibrium, and evaluate the last 30 years of each simulation. The drift in surface temperatures over the last 30 years, globally averaged, is less than $0.01 \mathrm{~K}$. Simulations are run at a resolution of $1.9^{\circ}$ latitude $\times 2.5^{\circ}$ longitude.

\section{b. Simple Land Interface Model}

The simple land model used here (the Simple Land Interface Model) allows us to individually modify different surface properties within a coupled climate model, to isolate their effect on climate. SLIM is described in greater detail in the supplemental material of this paper.

For this study, SLIM was written to couple into CESM in place of CLM. At every land location, the user can independently set each land surface property. These properties include the snow-free albedo, evaporative resistance, vegetation height (for aerodynamic roughness), the capacity of the land to hold water, the heat capacity and thermal resistance of the soil, the number and depth of soil layers, the snow-masking depth (the volume of snow required to mask the snow-free ground albedo), and the locations of glaciers. Heat diffusion through the soil is solved on a discretized vertical grid that is decoupled from the water budget of the land. Hydrology is represented using a bucket model, where the resistance to evaporation from the bucket is a combination of a user-prescribed "lid" resistance (comparable to the bulk stomatal resistance of a complex land model like CLM) and an additional resistance due to how empty the bucket is (as in the GFDL-LM2 model; Milly and Shmakin 2002; Anderson et al. 2004; Manabe and Bryan 1969). Given semi-realistic values for albedo, vegetation height, and evaporative resistance, SLIM can produce surface temperatures that differ less than $1 \mathrm{~K}$ to those from CLM5 over most regions using reanalysis atmospheric forcing data (see Figs. S2-S9 in the online supplemental material).

At each time step, the land model solves a linearized surface energy budget to calculate a surface temperature and surface fluxes of radiation, sensible and latent heat flux, and heat uptake by the ground. A simple snow model allows snow falling from the atmosphere to accumulate on the surface and mask the bare ground albedo; snow is removed from the surface either by sublimation to the atmosphere or by melting into the land surface.

\section{c. Analysis approaches}

For each surface property, we fit a least squares linear regression model of a climate variable (e.g., surface temperature) to the prescribed values of the surface property (Fig. 2). Each surface property value has 30 points, one annual mean value for each spun-up simulation year. When fitting our linear model, we track how linear the relationship between the change in global surface property (e.g., albedo in Fig. 2) and the response of the climate variable in question (surface temperature in Fig. 2) using the $r^{2}$ value of the linear relationship. We test if the slope is significantly different from zero using the $p$ value (where $p<0.05$ indicates a statistically significant relationship at the $95 \%$ confidence level).

To evaluate the climate response to physically meaningful changes in each surface property, we scale the slope by a somewhat arbitrary scaling factor chosen to show a maximum temperature change of roughly $1 \mathrm{~K}$ in the coupled simulations, which corresponds to maximum surface energy flux changes of approximately $10 \mathrm{~W} \mathrm{~m}^{-2}$. This corresponds to a scaling factor of -0.04 for albedo (the surface gets $4 \%$ darker), $50 \mathrm{~s} \mathrm{~m}^{-1}$ for evaporative resistance (increasing surface resistance), and $-0.5 \mathrm{~m}$ for vegetation height (response per $0.5 \mathrm{~m}$ shorter/smoother the surface becomes). For example, a slope of $-20 \mathrm{~K}$ per 1.0 increase in albedo is not physically meaningful, as albedo values only range between 0 and 1 . Instead, we scale the slope to get a change of $-0.8 \mathrm{~K}(-20 \mathrm{~K} \times 0.04)$ per $4 \%$ decrease in albedo. To evaluate the warming impact of each surface property, we look at the effects of decreasing albedo, increasing 


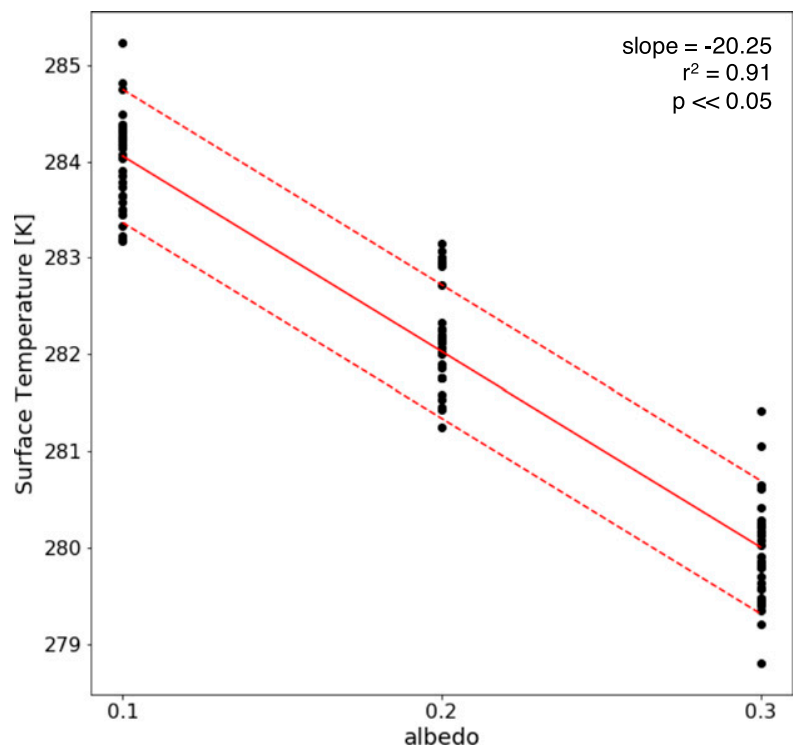

FIG. 2. Example of calculation of the slope $\partial \mathrm{atm} / \partial \ln$ f for the response of surface (skin) temperature to changing surface albedo at $42^{\circ} \mathrm{N}, 102.5^{\circ} \mathrm{W}$. Individual black dots show the annual mean temperature for a single year (30 years per spun-up simulation) at each of the three albedo levels. The solid red line shows the slope of the response, while the dashed red lines show plus and minus one standard error around the slope. Because this example has a strong response, the $p$ value, which we use to test if the slope is different from zero, is very small $\left(p \approx 10^{-47}\right)$.

evaporative resistance, and decreasing vegetation height. This slope value is calculated individually for each grid cell, and presented as the climate response to each scaled change in surface property in the rest of the paper.

In our offline simulations, the impact on surface energy fluxes and temperature of a change in a land surface property represents the response independent of any atmospheric response to the change in land surface property. That is, the changes are driven only by the surface energy budget adjustment to the local change in surface property (Fig. 1a), and not by any change in atmospheric temperature, cloud cover, etc., which may occur due to any interaction with the atmosphere (Figs. 1b,c). For example, even if the surface energy fluxes on the land surface changed dramatically in response to a change in some surface property, the atmospheric fluxes sent down to the land model would remain the same. Thus, the offline simulations give us an estimate of the direct response of the surface energy budget to a change in the land surface in isolation from any atmospheric changes-note that this is more of a theoretical concept, as in the real world the atmosphere and land are always free to interact.

In comparison, coupled simulations capture the direct surface energy budget response (i.e., the response we would expect in an offline simulation), changes in surface fluxes due to local atmospheric responses to the initial surface change (Fig. 1b), as well as changes in local surface fluxes due to remotely driven atmospheric responses (i.e., driven by land surface property changes elsewhere; Fig. 1c). We call the changes in the atmosphere driven by initial changes in land surface properties, which then go on to modify energy fluxes at the land surface, the atmospheric feedback to that initial land surface change.

\section{Results and discussion}

\section{a. Albedo}

The albedo (the fraction of incident radiation that is reflected) of different land surfaces varies greatly between vegetation and land cover types. Coniferous forest albedos range from 0.05 to 0.15 , deciduous forests from 0.15 to 0.20 , grasslands from 0.16 to 0.26 , and soils from 0.05 to 0.40 ; snow cover leads to land albedos of over 0.9 (Bonan 2002). We scaled our results so that they are relative to a 0.04 change in land surface albedo; physically, this can be thought of as a conservative approximation of the albedo difference between a coniferous and deciduous forest or between a deciduous forest and a grassland.

Albedo directly controls the amount of solar energy absorbed by the land surface and, as such, plays an important role in controlling land surface temperatures. If the land surface absorbs more energy in response to decreasing surface albedo, more energy must also leave the surface, either by an increase in turbulent energy fluxes (sensible and latent heat) or by an increase in longwave radiation emitted by the surface (increasing surface temperature). Over long time scales the storage of energy by the land surface is negligible.

\section{1) OFFLINE}

The differences in the pattern of surface temperature change in response to albedo in the offline simulations, where no atmospheric feedbacks are allowed, are caused by differences in 1) the change in absorbed solar energy (a function of downwelling solar radiation) and 2) the partitioning of energy into turbulent heat fluxes versus surface heating.

In the offline simulations, the surface temperature response to decreasing land surface albedo is largest in the midlatitudes and smallest at high latitudes (Fig. 3d; see also Fig. S10a). Because the incident sunlight is weaker at high latitudes, the same decrease in surface albedo results in a smaller net increase in absorbed solar radiation compared to lower latitudes (Fig. 4e). This means that in high latitudes there is less extra energy that the surface needs to get rid of (either through warming or through turbulent heat fluxes), and the total temperature 
$\Delta \mathrm{T}_{\mathrm{s}}$ coupled
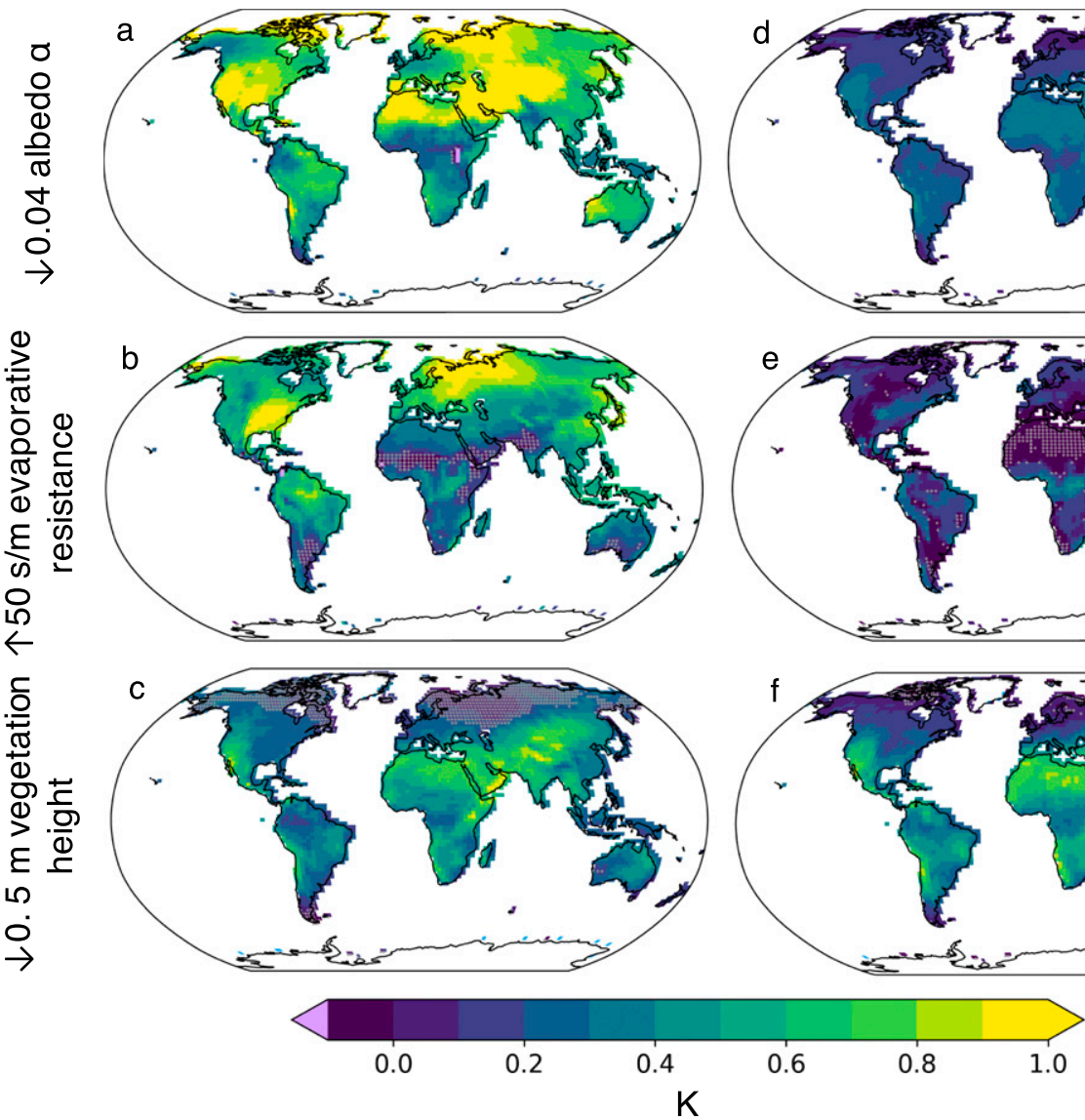

$\Delta \mathrm{T}_{\mathrm{s}}$ offline
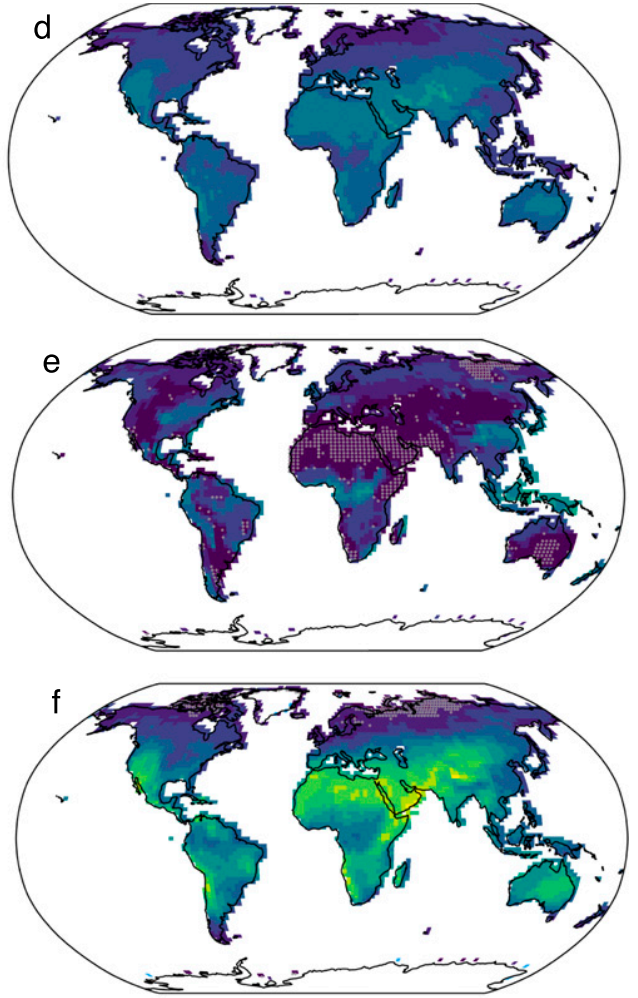

0

FIG. 3. Annual mean scaled surface temperature $T_{s}$ response (K) for (a)-(c) coupled simulations and (d)-(f) offline simulations, per (a),(d) 0.04 darkening of the surface albedo, (b),(e) $50 \mathrm{~s} \mathrm{~m}^{-1}$ increase in evaporative resistance, and (c),(f) 5.0-m decrease in vegetation height. Violet regions $\left(\Delta T_{s}<-0.1\right)$ indicate regions where the temperature cooled substantially in response to the prescribed surface change. Stippling indicates regions where the slope is not significantly different from zero $(p>0.05)$.

change is small. Conversely, surface temperature changes in the offline simulations are larger in regions with a large amount of incident solar radiation at the surface (the tropics and midlatitudes). Despite the fact that equatorial regions receive the most incoming solar radiation at the top of the atmosphere, the large amount of deep cloud cover over the tropics blocks a lot of solar radiation, and the largest amount of downwelling solar radiation at the surface in the annual mean actually occurs over northern Africa and the Arabian Peninsula (Fig. S11).

The surface temperature response to decreasing albedo in the tropics is smaller than in the midlatitude deserts not only because of the difference in the incident solar radiation at the surface, but also because of differences in the amount of water available on the land surface due to high tropical precipitation rates. As such, though decreasing albedo does lead to an increase in the total energy absorbed at the surface in the tropics (Fig. 4e), that excess energy is removed from the surface primarily by evaporating more water (Fig. 4h), negating the need for increased surface temperatures and changes in upward longwave radiation (Fig. 4f). The largest surface temperature changes in the offline simulations occur in sunny, dry regions such as the Sahara and Arabian Peninsula, where latent cooling is not able to occur and the excess absorbed solar energy is balanced by increased surface temperatures and sensible heat fluxes (Figs. 4f,g).

\section{2) Coupled}

In the coupled simulations, changes in energy fluxes are transmitted to the atmosphere, with potential resulting interactions and feedbacks between the land and the atmosphere. Interactions with the atmosphere could cause 
Coupled
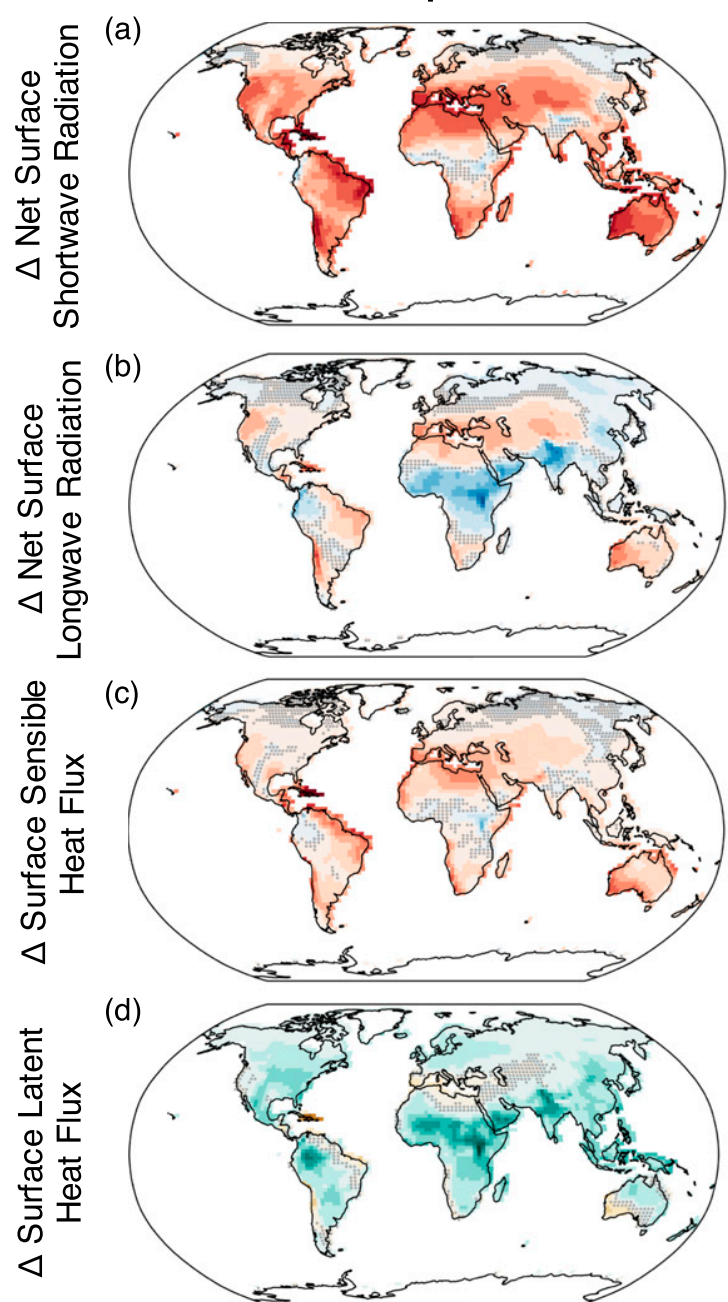

(e)

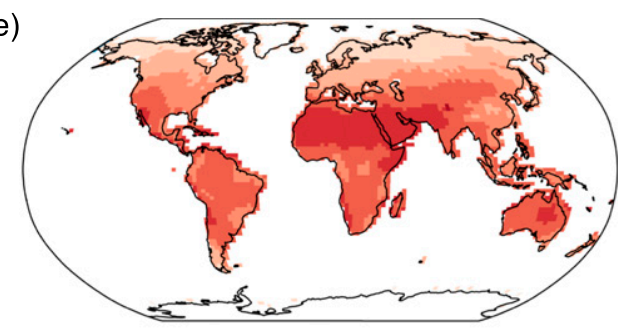

(f)

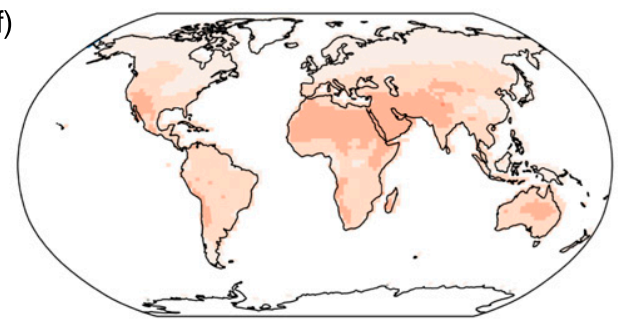

(g)

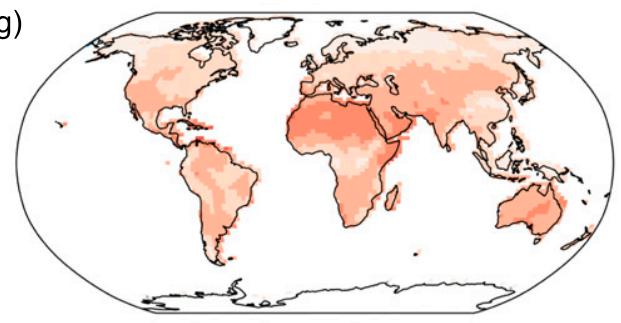

(h)

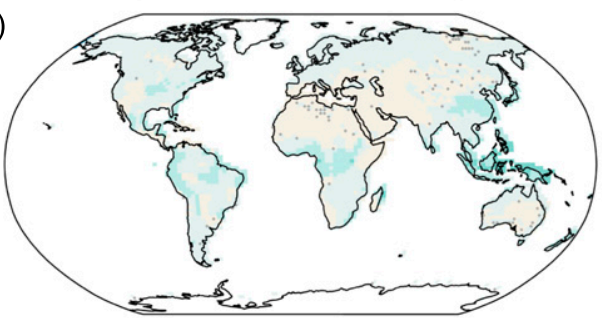

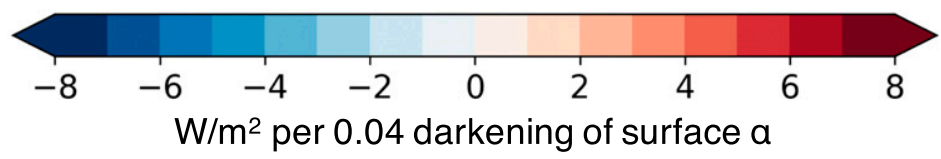

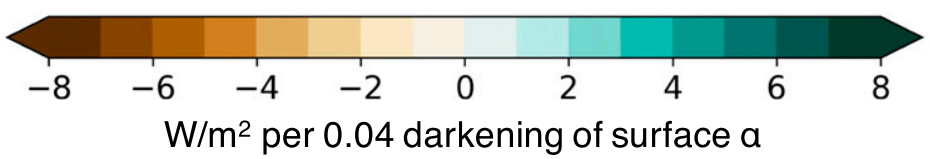

FIG. 4. Annual mean change in surface energy fluxes $\left(\mathrm{W} \mathrm{m}^{-2}\right)$ per 0.04 decrease in global land albedo, showing (a)-(d) fluxes from the coupled simulations and (e)-(h) offline fluxes: (a),(e) net shortwave radiation, (b),(f) net longwave radiation, (c), (g) sensible heat flux, and (d),(h) latent heat flux. Red (blue) indicates an increase (decrease) in net shortwave radiation, net longwave radiation, and sensible heat flux. Green (brown) indicates an increase (decrease) in latent heat flux. Stippling indicates regions where the response is not significant $(p>0.05)$.

further changes in surface climate through several pathways, three of which are discussed here. First, changes in atmospheric air temperature could modify the magnitude of downwelling longwave radiation and the surface-toatmosphere temperature gradient, which influences sensible heat flux. Second, changes in cloud cover could modify the magnitude of both downwelling shortwave and longwave radiation at the surface. Third, changes in humidity could modify the vertical moisture gradient, which influences latent heat flux.

In the coupled simulations, not only is the response of surface temperature to decreasing albedo much larger in 
magnitude compared with the offline simulations, but it is also drastically different in spatial pattern (Fig. 3a vs Fig. 3d). Rather than the high latitudes having the smallest surface temperature response to decreased albedo, they now have some of the largest warming signals (along with hot, dry regions in the midlatitudes). The magnitude of warming at the surface in the coupled simulations is larger than in the offline simulations in almost all regions, with the exception of equatorial Africa. When the atmosphere is allowed to respond (coupled simulations), decreasing the surface albedo still generally leads to an increase in absorbed shortwave radiation. However, the change in absorbed energy is smaller in magnitude and has a different spatial pattern than in the offline simulations, with near-zero changes in absorbed shortwave radiation in the parts of the tropics and high latitudes, and the largest increases in absorbed solar radiation occurring over the midlatitudes and parts of tropical South America (cf. Figs. 4a and 4d). Surprisingly, there are some locations where decreasing albedo actually leads to slightly less absorbed solar radiation at the surface. This response is most notable in the coupled simulation over equatorial Africa, and is the result of increased cloud cover over this region reducing the incident solar radiation (Fig. S12).

Across the tropics, decreasing albedo leads to much larger increases in latent heat flux in the coupled simulations than in the offline simulations, most notably over India, equatorial Africa, Indonesia, and the western Amazon (Fig. 4d). Many of these regions also stand out as having a decrease in net longwave radiation at the surface with decreased albedo, despite surface warming (Fig. 4b). Surface warming is accompanied by an increase in upward longwave radiation emitted from the surface, following the Stefan-Boltzmann equation $\mathrm{LW}^{\uparrow} \propto \sigma T_{s}^{4}$ (where $T_{s}$ is the radiative skin temperature of the land surface, and $\sigma$ is the Stefan-Boltzmann constant). However, when the atmosphere warms in response to surface warming, there is also an increase in downward longwave radiation at the surface; thus, more energy is being input to the land system as a result of a warmer atmosphere (Vargas Zeppetello et al. 2019). The net longwave radiation at the surface is the difference between the longwave radiation emitted upward, and the downwelling longwave radiation reaching the surface from the atmosphere. In some locations, the increases in upward longwave radiation (corresponding to increases in surface temperatures) are larger than the increases in downwelling longwave radiation (corresponding to a warmer atmosphere), resulting in decreased net longwave radiation at the surface as albedo decreases.

The increase in annual mean surface temperature at high latitudes is largest in autumn and winter (not shown), when the incoming insolation is very small. This is surprising, as decreasing surface albedo during dark months has a much smaller impact on absorbed shortwave radiation than decreasing albedo during bright months; moreover, much of the high-latitude land surface is covered with (bright) snow during the winter months, masking the direct change in surface albedo. This suggests that the high-latitude winter warming is not locally driven. Indeed, there is a significant increase in energy transport into the Arctic region from the midlatitudes [see section 3d(2) below], which should lead to high-latitude warming. Additionally, there is significant loss of sea ice (largest in September) for the reduced albedo simulations, which is likely due to a combination of increased energy transport to the Arctic and local warming from summer albedo changes triggering an ice-albedo feedback.

\section{b. Evaporative resistance}

Vegetation can directly control the evaporative resistance of a surface through the opening and closing of stomata on their leaves. The evaporative resistance of a surface is also controlled by soil properties, vegetation root depth, leaf area, and how much water is available in the soil. Here, we present results for a $50 \mathrm{~s} \mathrm{~m}^{-1}$ change in the evaporative resistance of the land surface. The total resistance to evaporation is a combination of the surface resistance (which we perturb) and the resistance associated with how dry the soil is. Changing the evaporative resistance of the land surface has no direct effect on the total amount of energy absorbed by the surface; rather, it controls the partitioning between latent and sensible heat fluxes (Fig. 5). In general we expect that a surface with higher resistance would have relatively more sensible and less latent heat flux, leading to higher surface temperatures relative to a surface with lower resistance.

\section{1) OFFLINE}

Our offline simulations show the largest change in surface temperature in the wettest regions of the tropics (Fig. 3e). This response is intuitive: increasing resistance in these regions causes a large reduction in latent heat flux (Fig. 5h), which is compensated for by surface warming, increased sensible heat flux, and increased upward longwave radiation (Figs. 5f,g). Dry regions (e.g., the Sahara and central Australia) have no temperature response to increasing surface resistance in the offline simulations; these regions have very little water on the land surface and near-zero latent heat fluxes, so making it more difficult to evaporate water does not result in any substantial changes to the actual magnitude of latent heat flux, and thus there is no compensating change in the other terms of the surface energy budget. 
Coupled
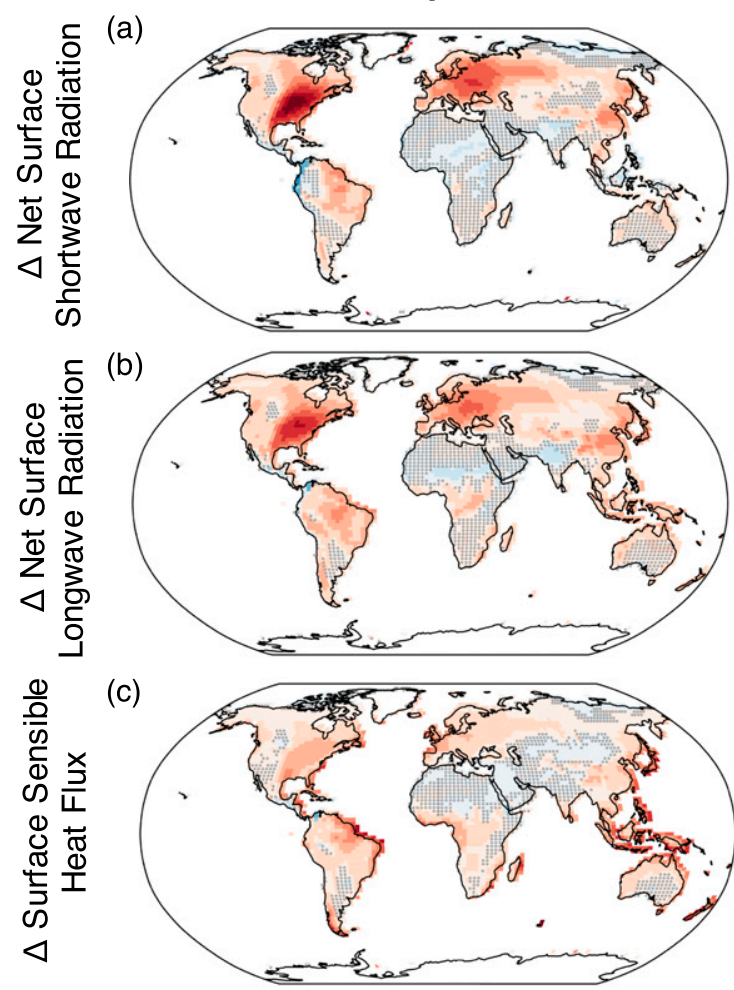

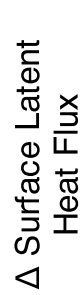

(d)

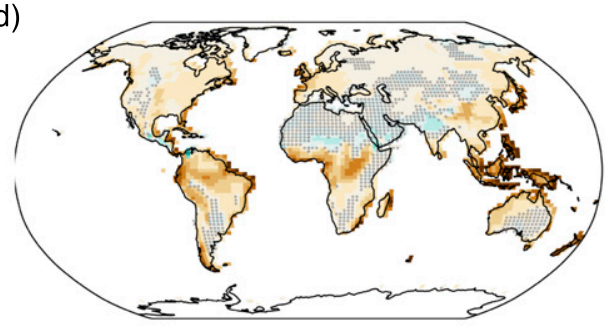

(e)

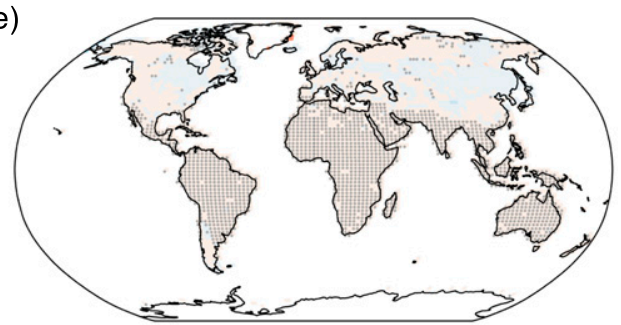

(f)

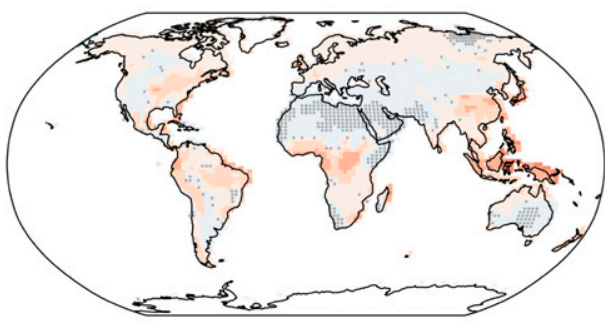

(g)

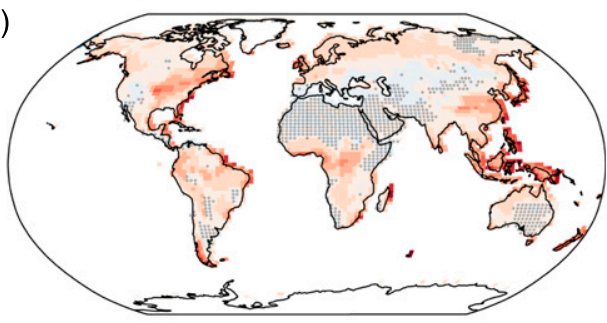

(h)

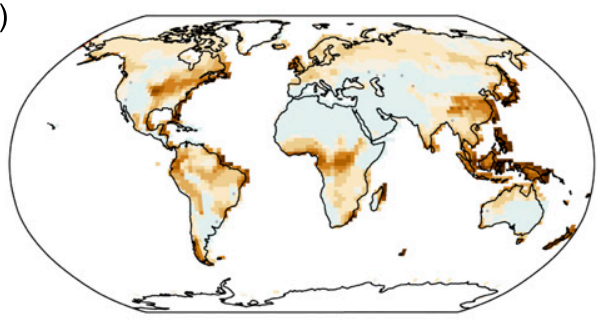

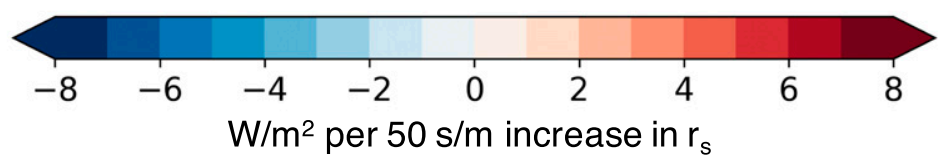

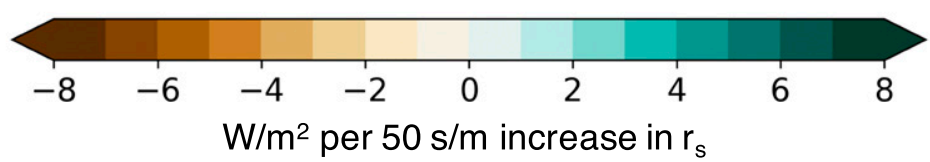

FIG. 5. Annual mean change in surface energy fluxes $\left(\mathrm{W} \mathrm{m}^{-2}\right)$ per $50 \mathrm{~s} \mathrm{~m}^{-1}$ increase in evaporative resistance, showing (a)-(d) fluxes from the coupled simulations and (e)-(h) offline fluxes: (a),(e) net shortwave radiation, (b),(f) net longwave radiation, (c),(g) sensible heat flux, and (d),(h) latent heat flux. Red (blue) indicates an increase (decrease) in net shortwave radiation, net longwave radiation, and sensible heat flux. Green (brown) indicates an increase (decrease) in latent heat flux. Stippling indicates regions where the response is not significant $(p>0.05)$.

The amount of shortwave radiation absorbed at the surface is only a function of the downwelling shortwave radiation and the albedo of a surface; as such, increasing evaporative resistance in offline simulations has no impact on the absorbed solar energy at the surface (Fig. 5e). Instead, evaporative resistance directly controls the partitioning of energy between turbulent heat fluxes, with the largest temperature responses occurring in warm locations with large amounts of water available to evaporate, such as Indonesia and the coastal regions of the Amazon (Fig. 5h). These regions have large latent heat fluxes in the mean state, because of a 
combination of plenty of precipitation (thus lots of water available to evaporate), and plenty of energy entering the land system. Thus, increasing evaporative resistance leads to large magnitudes of change in latent heat fluxes; energy that formerly was used for evaporation instead results in surface heating.

\section{2) Coupled}

As with albedo, the pattern and magnitude of the surface temperature response to increasing evaporative resistance over land have a larger magnitude and a spatially distinct pattern in our coupled simulations compared to their offline counterparts (Fig. 3b). Rather than in the wettest tropical regions, our coupled simulations have the largest changes in surface temperature in response to decreasing surface resistance in the middle to high latitudes. Dry regions in the subtropics have the smallest change in surface temperature when evaporative resistance is increased, but these regions still show more warming than in the offline simulations. Although temperature changes in the tropics are small, the decreases in latent heat flux in the wettest regions of the tropics, such as the Maritime Continent, are the largest of anywhere on the globe.

One of the largest changes in surface temperature in response to increased evaporative resistance occurs over southeastern North America. Over this region, there is a slight decrease in evaporation in both the coupled and offline simulations (cf. Figs. 5d and 5h). However, the changes to temperature and energy fluxes are otherwise quite different. In the coupled simulation, increased evaporative resistance at the land surface drives warming and drying of the regional atmosphere. The warming and drying of the lower troposphere in this region leads to a decrease in relative humidity and a decrease in low cloud cover (not shown). The reduction in cloud cover in turn allows more solar radiation to reach the surface, causing surface temperatures to rise. Averaged over the region $32^{\circ}-45^{\circ} \mathrm{N}, 85^{\circ}-100^{\circ} \mathrm{W}$ a $50 \mathrm{~s} \mathrm{~m}^{-1}$ increase in evaporative resistance leads to a $6.2 \mathrm{~W} \mathrm{~m}^{-2}$ increase in absorbed solar radiation in the coupled simulations. This increase in energy into the land system over this region results in a temperature increase of roughly $0.9 \mathrm{~K}$ in the coupled simulation, compared to a warming of only $0.2 \mathrm{~K}$ in the uncoupled simulation (per $50 \mathrm{~s} \mathrm{~m}^{-1}$ increase in evaporative resistance). This cloud feedback is particularly interesting, as evaporative resistance cannot directly modify the amount of energy absorbed by the surface.

The decreases in latent heat flux in response to increased evaporative resistance are actually smaller in the coupled simulations than in the offline simulations. This is because in the coupled simulations, as the air dries in response to reduced evaporation, the atmospheric demand for water increases.

\section{c. Roughness}

\section{1) OFFLINE}

Changing the height of vegetation changes the aerodynamic roughness of the land surface, and thus how effectively turbulent energy fluxes can be exchanged with the atmosphere. Decreasing surface roughness makes it harder to remove energy from the land surface by turbulent mixing, but has no direct impact on the total amount of energy entering the land system (Fig. 6e). Decreasing the roughness leads to a reduction in sensible heat flux, balanced by a corresponding increase in longwave radiation, with little to no impact on latent heat flux (Figs. 6f-h).

The strongest impacts on surface energy fluxes occur in regions with large sensible heat fluxes, such as the subtropical desert regions. Note that the pattern of temperature response is similar for both the short and tall regimes of changes in vegetation heights, but that the height change required to scale responses to roughly $1 \mathrm{~K}$ shifts from $0.5 \mathrm{~m}$ in the short regime to $10.0 \mathrm{~m}$ in the tall regime (see Fig. S16 and further discussion in the supplement). This reflects a shift in how efficiently a given change in surface aerodynamic roughness can impact energy fluxes and surface temperatures-when the land is relatively smooth, small changes in aerodynamic roughness are important; when the land is relatively rough, small changes have little impact.

\section{2) Coupled}

Unlike decreasing albedo and increasing evaporative resistance, which result in larger surface temperature changes with different spatial patterns in the coupled compared to the offline simulations, decreasing surface roughness results in a similar pattern and magnitude of warming in the coupled versus offline simulations (Figs. 3c,f). Also unlike the albedo and evaporative resistance cases, which modify both the surface temperature (radiative skin temperature) and the near-surface air temperature in the coupled simulations, the temperature response in the coupled roughness simulations is primarily restricted to the surface itself (Fig. 7).

In both the offline and coupled experiments, decreasing the vegetation height (and thus the surface roughness) has the largest impact on temperature in the warmest regions of the globe, with much smaller annual mean temperature increases in the high latitudes. As the roughness of a surface should impact how efficiently turbulent heat can be moved away from the surface, it should have the largest impact on surface temperatures in regions where turbulent heat fluxes play a large role in balancing the surface energy budget. 

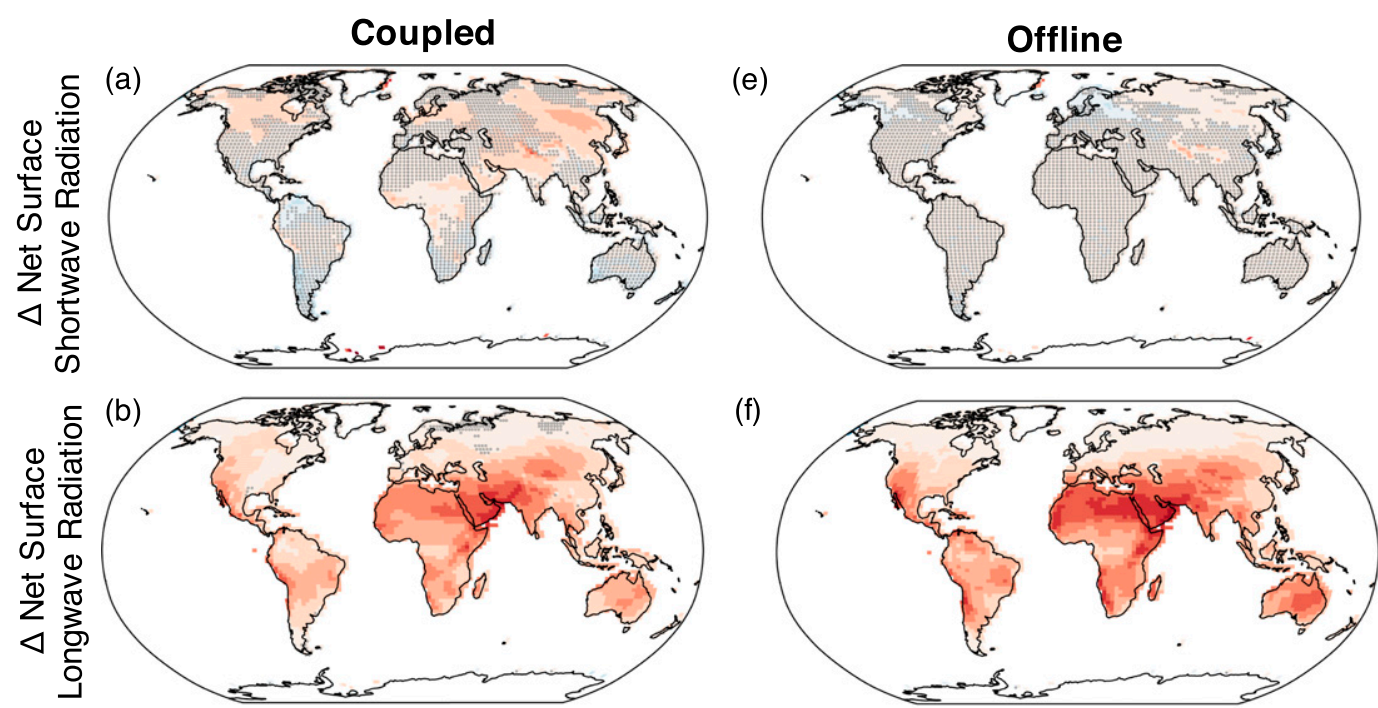

(f)
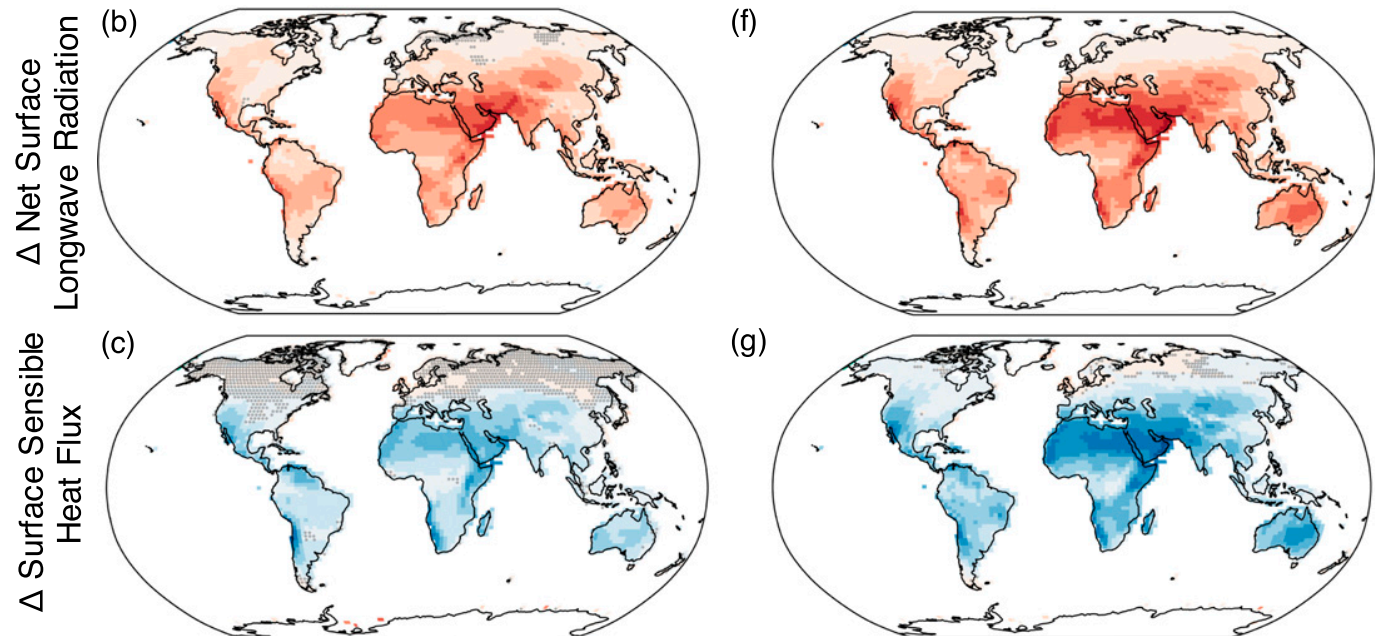

(g)

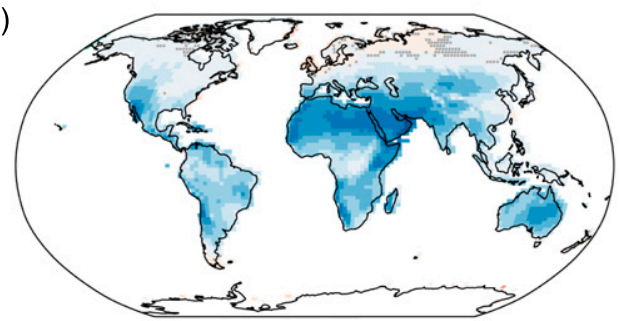

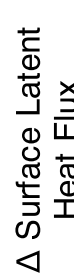

(d)

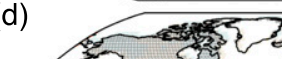

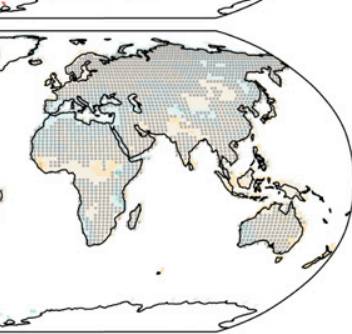

(h)

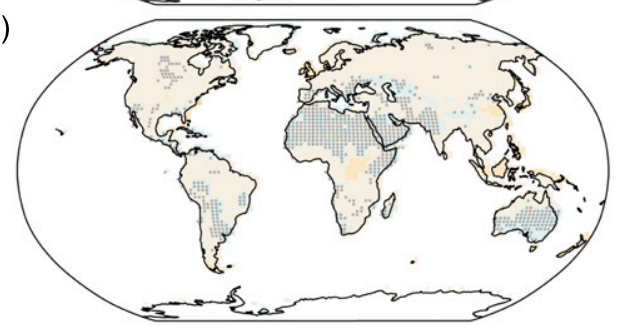

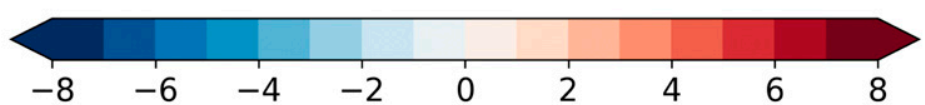

$\mathrm{W} / \mathrm{m}^{2}$ per $0.5 \mathrm{~m}$ decrease in vegetation height

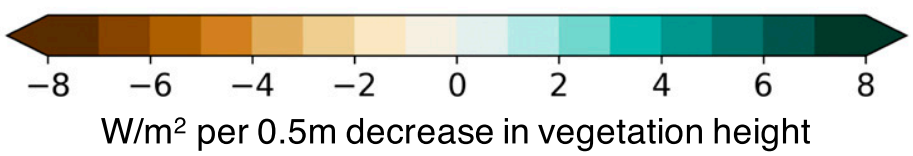

FIG. 6. Annual mean change in surface energy fluxes $\left(\mathrm{W} \mathrm{m}^{-2}\right)$ per $0.5-\mathrm{m}$ decrease in vegetation height, showing (a)-(d) fluxes from the coupled simulations and (e)-(h) offline fluxes: (a),(e) net shortwave radiation, (b),(f) net longwave radiation, (c), (g) sensible heat flux, and (d),(h) latent heat flux. Red (blue) indicates an increase (decrease) in net shortwave radiation, net longwave radiation, and sensible heat flux. Green (brown) indicates an increase (decrease) in latent heat flux. Stippling indicates regions where the response is not significant $(p>0.05)$.

\section{d. Feedbacks}

In the real world, as well as in our coupled simulations, the land surface does not respond to forcing in isolation; changes in surface energy fluxes are communicated to the atmosphere and can drive changes in atmospheric temperature, humidity, cloud cover, and circulation as noted above. Many of these atmospheric responses to changes in surface energy fluxes can then feed back on the surface energy budget itself. For example, a change in cloud cover driven by some initial surface change could lead to a subsequent change in solar radiation reaching the surface, which in turn drives further changes in the surface energy budget 


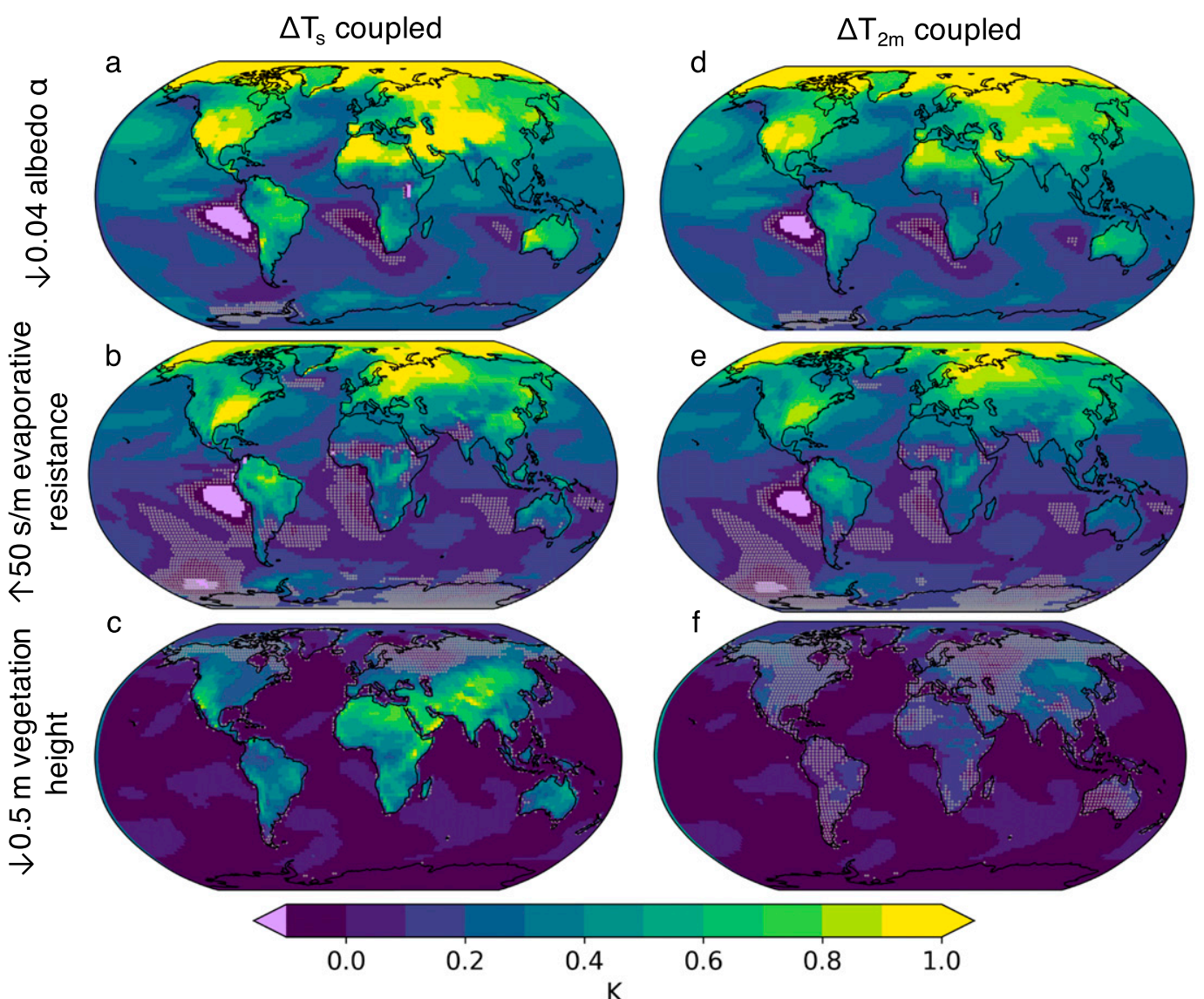

FIG. 7. Change in (a)-(c) surface temperature and (d)-(f) 2-m air temperature (K) per (a),(d) 0.04 decrease in land surface albedo, (b),(e) $50 \mathrm{~s} \mathrm{~m}^{-1}$ increase in land surface evaporative resistance, and (c),(f) $0.5-\mathrm{m}$ decrease in land surface vegetation height. Stippling indicates regions that are not significant $(p<0.05)$, while violet shows areas where the temperature response is less than $-0.1 \mathrm{~K}$.

(Fig. 1b). Additionally, the atmosphere can transmit information (e.g., changes in circulation, or fluxes of water, heat, or clouds) from one atmospheric column to another, such that a change in the land surface in one region can, through these remote atmospheric feedbacks, influence the surface energy budget in a remote region (Fig. 1c).

\section{1) TOtAl ATMOSPHERIC FEEDBACK}

The differing surface fluxes between simulations where the atmosphere is or is not allowed to respond result in remarkably different patterns and magnitudes of surface temperature change for the same imposed surface property change as described above. Because the atmosphere can respond to changes in surface fluxes, modifying land albedo, evaporative resistance, and roughness can lead to large changes in cloud cover, snowfall, sea ice, and energy transport, all of which can feed back on the surface energy fluxes over the land surface.
We define the total atmospheric feedback on surface climate to be the difference between the coupled simulation and the offline simulation (Fig. 8; for surface air temperature, this would be the difference between the left and right columns of Fig. 3). For albedo and evaporative resistance, the extratropics have up to $1 \mathrm{~K}$ of additional surface warming when the atmosphere is allowed to respond to changes in surface energy fluxes driven by the modified land surface properties.

To identify the strength of the atmospheric feedbackthat is, what percentage of the total warming signal comes from interactions with the atmosphere-we calculate the percentage change in surface temperature between the coupled simulation and the offline simulation:

$$
\text { Feedback strength }=\frac{\text { Coupled }- \text { Offline }}{\mid \text { Coupled } \mid} \times 100 .
$$

For albedo, over $50 \%$ of the change in surface temperature comes from interactions with the atmosphere 


\section{Feedback Pattern (coupled - offline)}
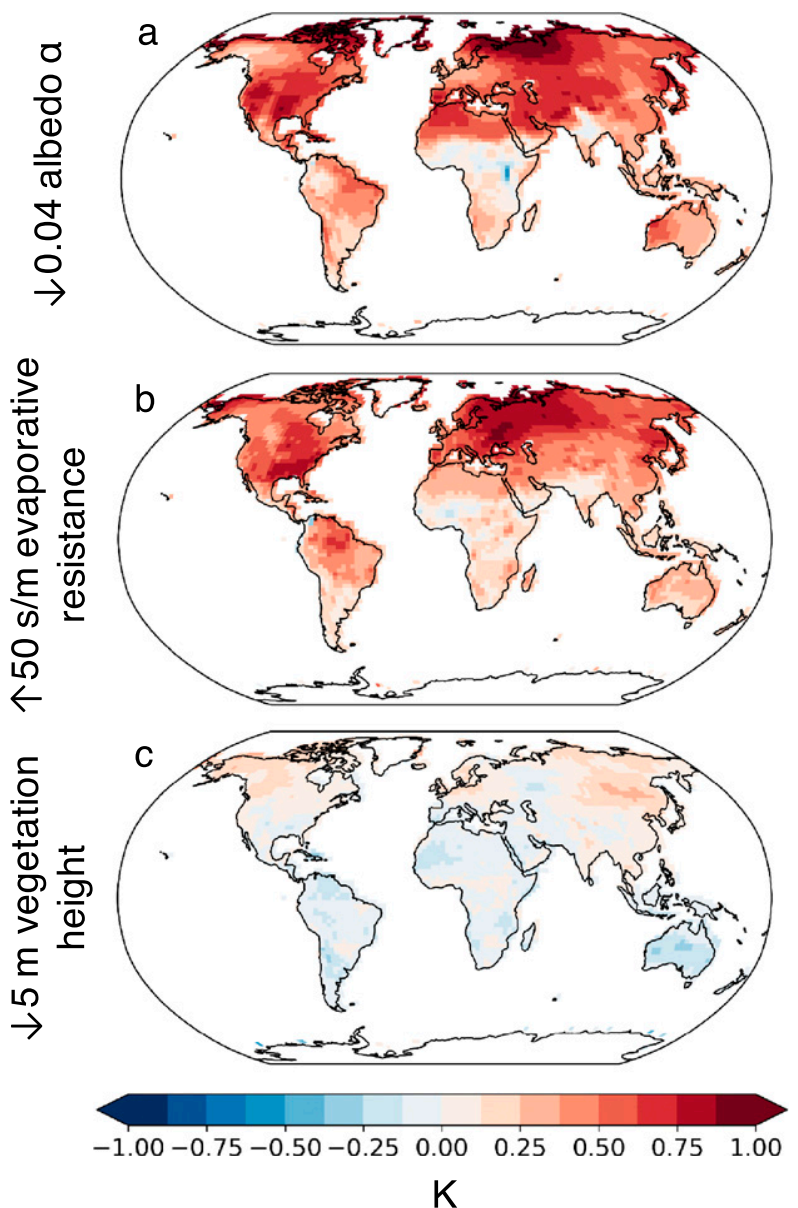

FIG. 8. Difference in surface temperature response in coupled minus offline simulations for (a) albedo, (b) evaporative resistance, and (c) vegetation height.

over more than $80 \%$ of global, nonglaciated land area, with as much as $75 \%$ of the temperature response coming from the atmosphere over $28 \%$ of land area. This is even larger for evaporative resistance; over $50 \%$ of the surface temperature increase comes from atmospheric feedbacks over $84 \%$ of nonglaciated land areas, with increases as large as $75 \%$ over $64 \%$ of land area (Fig. 9). This suggests that vegetation changes that significantly alter the color of the land surface or change how difficult it is to remove water from the land surface (such as the conversion of a forest to a grassland) have significant impacts on surface climate due to changes in the atmosphere in response to the initial vegetation change.

\section{2) IMPACT ON GLOBAL ATMOSPHERIC CIRCULATION}

In addition to changes in temperature driven by changes to the local surface energy budget, decreasing albedo and increasing evaporative resistance both drive
Feedback Strength (\% change)
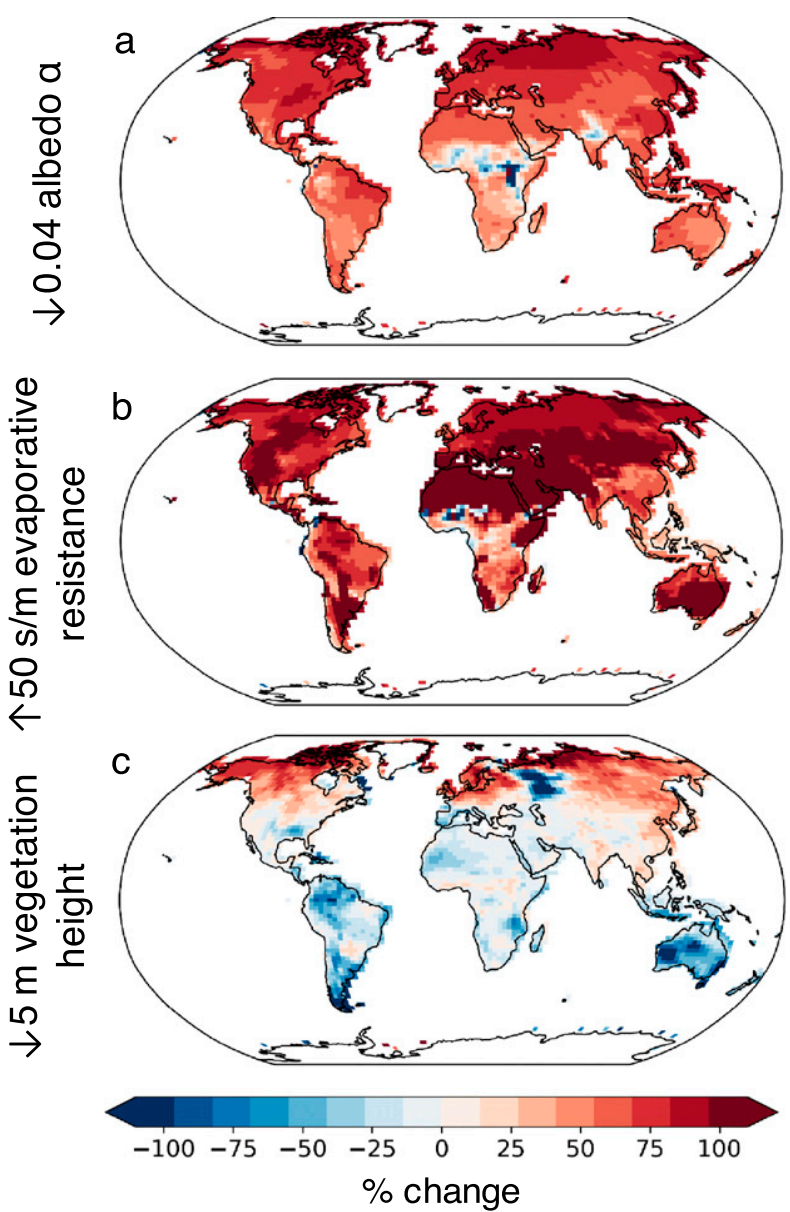

FIG. 9. Atmospheric feedback strength (percentage change) for (a) albedo, (b) evaporative resistance, and (c) vegetation height.

changes in large-scale atmospheric circulation. A northward shift of the Hadley circulation results in a significant change in northward energy transport by the atmosphere (Fig. 10a). When excess energy is absorbed in the Northern Hemisphere the Hadley circulation shifts to move energy from the energy-rich Northern Hemisphere to the Southern Hemisphere, causing the intertropical convergence zone to shift toward the energy-rich hemisphere (Fig. 10b). This response is well documented in slab-ocean models (Chiang and Bitz 2005; Kang et al. 2008; Swann et al. 2012; Frierson and Hwang 2012; Chiang and Friedman 2012; Laguë and Swann 2016) and also found in models with dynamical oceans (Broccoli et al. 2006). If such an energy gradient is established, we expect to see this large-scale circulation response.

In the case of albedo, a darker surface directly increases the amount of energy absorbed by the land surface. Because the Northern Hemisphere has more 


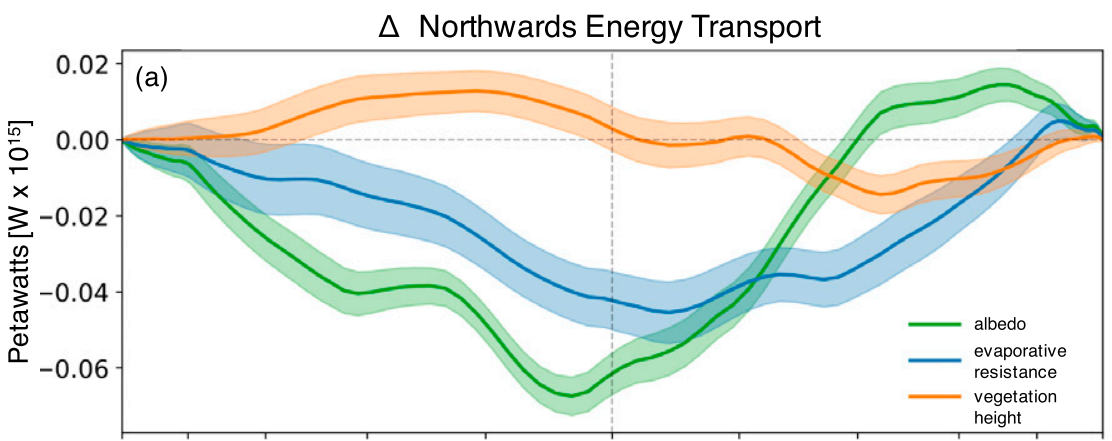

$\Delta$ Zonal Mean Precipitation

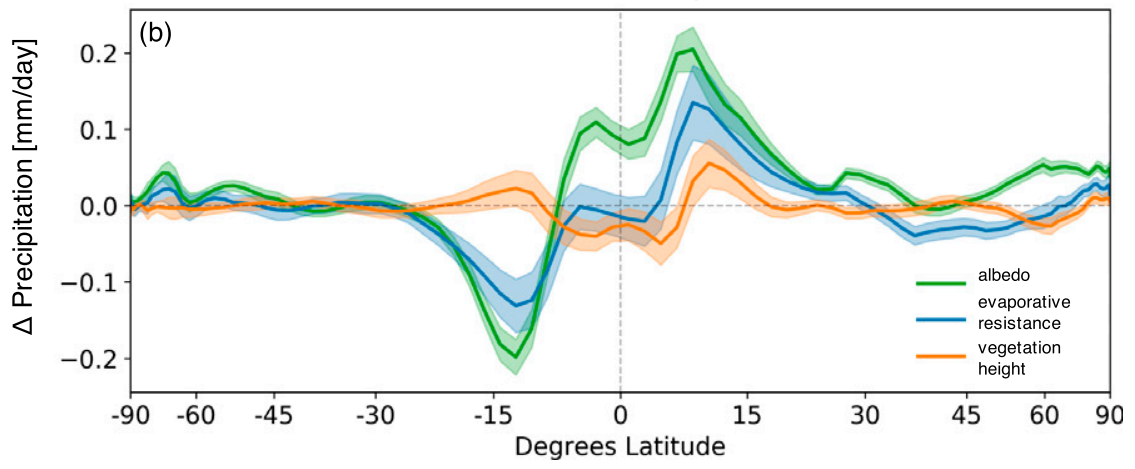

FIG. 10. Change in (a) northward energy transport (PW) and (b) zonal-mean precipitation $\left(\mathrm{mm} \mathrm{day}^{-1}\right)$ per 0.04 decrease in albedo (green), $50 \mathrm{~s} \mathrm{~m}^{-1}$ increase in evaporative resistance (blue), and $0.5-\mathrm{m}$ decrease in vegetation height (orange). Solid lines show the annual mean change in each field per change in each surface property. Shading indicates plus and minus one standard deviation around that mean change. Northward energy transport $F_{\phi}$ at each latitude $\phi$ is calculated as $F_{\phi}=\int_{-\pi / 2}^{\phi} \int_{0}^{2 \pi} R_{\mathrm{TOA}} a^{2} \cos \phi d \lambda d \phi$, where $a$ is the radius of Earth, $R_{\mathrm{TOA}}$ is the net radiation at the top of the atmosphere, $\phi$ is latitude, and $\lambda$ is longitude.

land-in particular, more nonglaciated land (we only modify nonglaciated land in this study) - than the Southern Hemisphere, decreasing land albedo globally results in more energy being absorbed by the surface in the Northern Hemisphere than in the Southern Hemisphere. The resulting energy gradient causes a southward shift in the Hadley circulation, evident in the increased southward energy transport across the equator. However, decreasing land albedo also has the effect of slightly increasing the energy transport from the northern midlatitudes into the Arctic, leading to highlatitude warming driven by the nonlocal albedo changes in the tropics and midlatitudes.

Evaporative resistance, unlike albedo, does not directly change the amount of energy absorbed by the surface; rather, it changes the partitioning of energy between sensible and latent heat. As such, it is surprising that increasing evaporative resistance drives a large, significant decrease in northward energy transport (blue line in Fig. 10a). We find that increasing evaporative resistance drives a decrease in cloud cover over many land areas; this causes an increase in downwelling shortwave radiation at the surface, and thus an increase in net shortwave energy absorbed at the surface despite no change in surface albedo (Fig. S12b, Fig. 5a). This introduces the hemispheric energy imbalance required to drive the observed large-scale shifts in energy transport.

Changing the roughness of the surface has only a weak impact on the total amount of energy absorbed by the land, and as such we see only small changes in northward energy transport and zonal mean precipitation (orange lines in Fig. 10).

\section{3) RESPONSE OVER OCEANS}

Changes in land surface properties drive changes in surface climate not only over the land, but also over the oceans. The slab-ocean model employed in these simulations allows SSTs and sea surface energy fluxes to respond to changes in the atmosphere (although heat transport within the ocean is held fixed). As such, atmospheric signals driven by changes in the land surface 
can propagate over the oceans, impacting SSTs, oceanic clouds, and precipitation, and potentially reaching farremoved land surfaces. Unlike the climate response over land regions in the fully coupled simulations, where the change in climate may be coming directly from the change in the land surface at that grid cell, or from atmospheric responses to remote changes in the land surface, the climate response over the ocean must inherently be a remote response to changes in the land surface, given that the ocean surface was not directly modified in any of our simulations.

When we make the land surface darker (reduce albedo), there is a large warming response over the Arctic Ocean, caused by a strong sea ice feedback where Arctic warming leads to loss of sea ice, which amplifies highlatitude warming (Fig. 7). The warming that initially drives the sea ice loss is a combination of both local warming from land in the northern high latitudes, as well as from an increase in energy transport into the high northern latitudes (Fig. 10a). With a darker land surface, the increase in absorption of solar radiation over land drives increased air temperatures over land; this warming is then advected by the atmosphere, resulting most notably in increased SSTs downwind of landmasses in the Northern Hemisphere. In contrast to the Northern Hemisphere warming over the oceans, in the Southern Hemisphere the temperature responses over the cloud decks west of South America, southern Africa, and Australia are near zero or negative. This cooling is caused by an increase in low cloud cover over these regions, which in turn is supported by increase subsidence over these low cloud decks (Fig. S15). Determining whether the increased subsidence is due to the direct albedo change of the neighboring continent (e.g., setting up a local east-west, Walker-like circulation) or is driven by the changes in large-scale atmospheric circulation (e.g., increased subsidence as a result of a shifting ITCZ) would require further simulations and is not the focus of this study.

\section{e. Inverse relationship}

Thus far, we have considered the response of various climate variables (e.g., $T_{s}$, the surface energy budget, clouds) as the change in that climate variable per incremental change in the magnitude of a surface property (albedo, evaporative resistance, or roughness); that is, we have considered the slope $\partial \mathrm{atm} / \partial \mathrm{ln} d$. However, in order to compare the relative impact of changes in different surface property types, it would be useful to know how much of a change in each property is needed to cause the same amount of temperature response. We can use our simulations to consider the inverse relationship $\partial \operatorname{lnd} / \partial \mathrm{atm}$. By scaling $\partial \operatorname{lnd} / \partial \mathrm{atm}$ such that $\partial \mathrm{atm}=0.1 \mathrm{~K}$, this relationship can be interpreted as the magnitude of global change in some surface property (albedo, evaporative resistance, or roughness) required to drive a $0.1-\mathrm{K}$ increase in surface temperature at any particular location (Fig. 11). A similar calculation can be applied to the offline simulations, which do not account for any atmospheric feedbacks; in that case, we calculate the local change in surface albedo required to drive a $0.1-\mathrm{K}$ change in local surface temperature, with no interaction effects from the local atmosphere, and no temperature effects from remote albedo change.

In the coupled simulations, only a $0.01(1 \%)$ decrease in global land surface albedo is required to drive $0.1 \mathrm{~K}$ of warming over $85.3 \%$ of land areas (Fig. 11a). This is well within the range of actual surface albedo changes associated with vegetation change, with grass albedos alone ranging from 0.16 to 0.26 (Bonan 2002). In the offline simulations, only $14.9 \%$ of land areas achieve a $0.1-\mathrm{K}$ warming with a $1 \%$ decrease in global land albedo (Fig. 11d).

To achieve a $0.1-\mathrm{K}$ temperature increase at any given location from global-scale changes in evaporative resistance, much larger changes in evaporative resistance are required in the offline versus the coupled simulations (Figs. 11b,e). For example, to see $0.1 \mathrm{~K}$ of warming over southwestern North America, a 5-10 $\mathrm{s} \mathrm{m}^{-1}$ increase in global land evaporative resistance would be required in the coupled simulations, while a change of over $20 \mathrm{~s} \mathrm{~m}^{-1}$ would be required in the offline simulations. The offline simulations require much larger changes in global land evaporative resistance to drive a $0.1-\mathrm{K}$ local temperature (Fig. 11e), largely because the warming response to increased evaporative resistance in the coupled simulations is due to changes in cloud cover that do not occur in the offline simulations. Only in some very wet areas, such as Indonesia, does a change in evaporative resistance translate to a substantial temperature change in the offline simulations.

Decreasing global land surface vegetation height by $<0.1 \mathrm{~m}$ or less leads to $0.1 \mathrm{~K}$ of surface temperature change across most of the low to midlatitudes, with smaller height changes required in hot, arid regions (Figs. 11c,f). In the high latitudes, where the air is frequently warmer than the surface, particularly during winter, it is not clear that decreasing vegetation height in these regions should lead to warming. Because atmospheric feedbacks play a smaller role in the local climate impact of changing vegetation height, the offline map can be interpreted as an indicator of where a local change in surface roughness is likely to result in a substantial change in local surface temperature. 

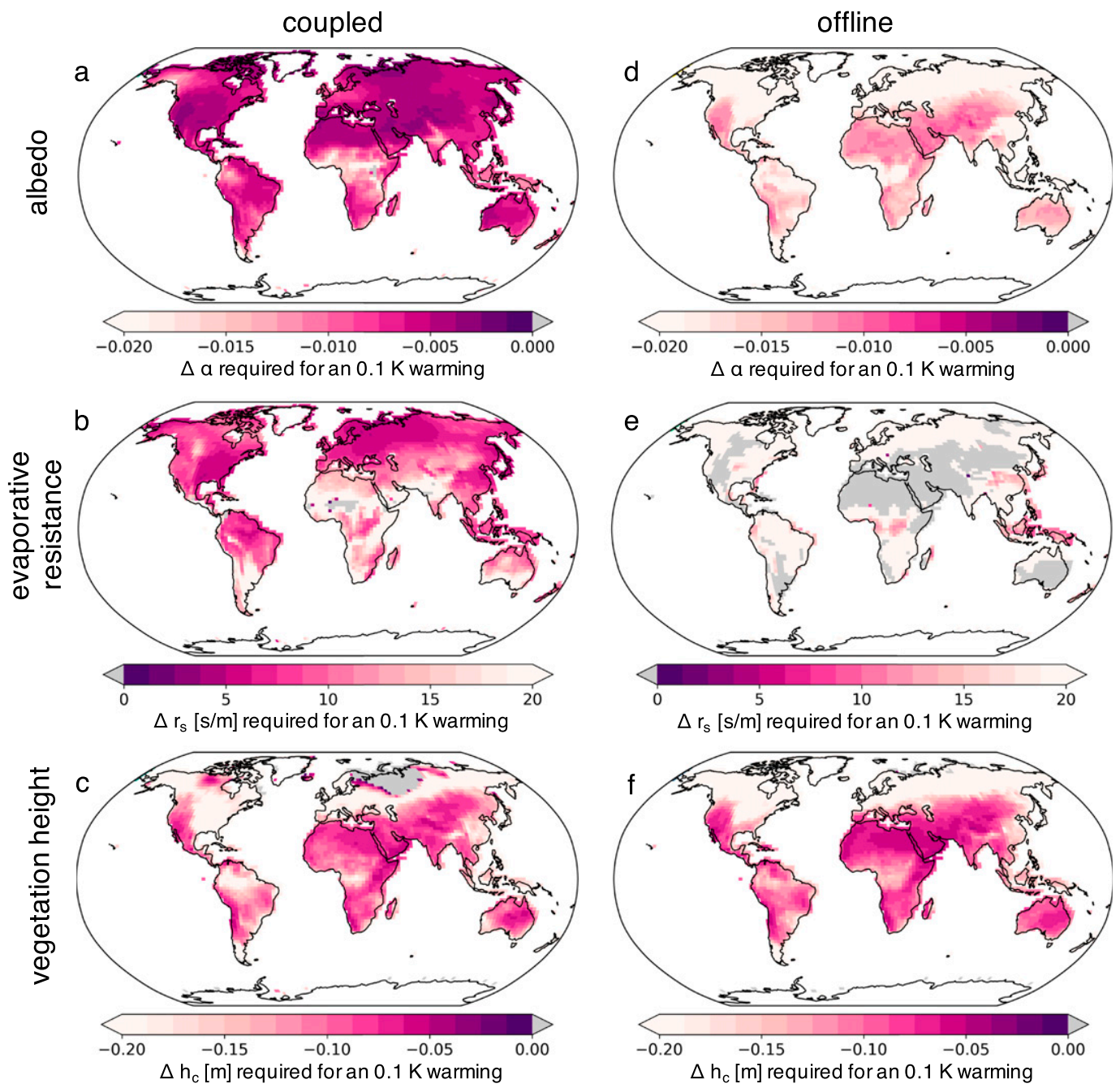

FIG. 11. Change in surface property required to drive an 0.1-K warming in the (a)-(c) coupled and (d)-(f) offline model simulations for (a),(d) albedo, (b),(e) evaporative resistance, and (c),(f) vegetation height. Note that negative numbers for albedo (darker colors) mean a decrease in albedo, positive numbers for evaporative resistance mean an increase in resistance, and negative numbers for vegetation height mean a reduction in vegetation height (smoother surface). Grayed areas show regions where decreased albedo, increased resistance, and decreased vegetation height cool (typically regions that are not significant in Fig. 3).

\section{f. Comparison to Davin and de Noblet-Ducoudré (2010)}

Davin and de Noblet-Ducoudré (2010) used a global climate model to explore the effects of global deforestation. Our results are consistent with Davin and de Noblet-Ducoudré (2010) in that increases in global land surface albedo lead to global-scale cooling; the largest temperature changes in their study occur at high latitudes, while our largest temperature changes occur in midlatitudes. Additional differences could result both from the spatially nonuniform surface changes used in Davin and de Noblet-Ducoudré (2010), from the fact that they used a fully dynamic rather than slab ocean, as well as from model dependency of results. Our work builds upon Davin and de Noblet-Ducoudré (2010) in two notable ways: first, by exploring the scaling relationship between different magnitudes of change in albedo, evaporative resistance, or vegetation height and the resulting climate effect, and second, by quantifying how much of the climate response to global changes in each land surface property was the result of atmospheric feedbacks.

\section{g. Caveats and limitations}

In this study we have established that the feedbacks from the atmosphere are large, comprising for example $75 \%$ or more of the total response of surface temperature to a change in surface resistance over $64 \%$ of land 
area. However, atmospheric feedbacks can be local (a change in the atmosphere above some location due to a change in land properties at that location) or remote (a change in the atmosphere above some location due to a change in land properties at a different location). We can see this effect clearly over the oceans where the climate response must be entirely remote, as the surface of the ocean is never directly modified in this study. However with our simulations alone, we cannot fully separate the effects of local versus remote atmospheric feedbacks over land because all land areas are perturbed at the same time; doing so will be left for future studies.

We present the response of surface fluxes and radiative skin temperatures to changes in different land surface properties. It is also important to consider how changes in each surface property impact near-surface air temperature, as this is the temperature humans experience from day to day. In the case of albedo and evaporative resistance, the 2-m air temperature is only slightly damped compared to the radiative skin temperatures (Figs. 7a,b,d,e). However, the change in the 2-m air temperature does not necessarily mirror the change in the surface (radiative) temperature of the land surface. This is particularly evident when comparing the effect of changes in roughness on surface versus $2-\mathrm{m}$ air temperature (Figs. 7c,f); while albedo and evaporative resistance result in warming both of the land surface and of the air in the coupled simulations, the magnitude of surface temperature response to decreasing roughness is much larger than that of 2-m air temperature.

In this study we aim to isolate the effect of individual surface properties on climate, and so in each experiment we modify a single land property at a time. When considering the climate impact of actual land use change, for example, changing from a forest to a grassland, multiple properties of the land surface are changed simultaneously. It is possible that modifying multiple surface properties at the same time and in different patterns leads to nonlinear responses that we have not addressed in the results presented here, but are an area for future study. Identifying which surface property dominates when all the surface properties associated with a given change in vegetation are considered is especially important given this uncertainty is one of the main reasons vegetation change drives different responses across models (Pitman et al. 2009; de Noblet-Ducoudré et al. 2012). Additionally, the strength of the atmospheric feedbacks presented here are the results of a single atmospheric model (CAM5); other atmospheric models could show stronger or weaker responses to changes in the land surface, particularly with regard to cloud cover. In particular, the strong response of low cloud cover to changes in evaporative resistance from the land surface is likely to be highly dependent on the shallow convection scheme used; CAM5 used in this study uses the University of Washington shallow cumulus parameterization (Park and Bretherton 2009; Neale et al. 2012).

\section{Summary and conclusions}

We evaluated the sensitivity of the land surface energy budget and land surface temperatures to changes in three individual land surface properties (albedo, evaporative resistance, and aerodynamic roughness). Changes in land albedo result in more absorbed incoming shortwave radiation, which leads to large surface temperatures changes in water-limited regions; temperature changes are small, but changes in latent heat flux are large, in regions with ample terrestrial water availability. Albedo has the largest impact on surface temperatures in warm, sunny regions in the offline simulations, but much larger and spatially broader impacts on surface temperatures across the middle and high latitudes in the coupled simulations due to largescale interactions with the atmosphere. Changes in evapotranspiration do not directly affect the amount of energy absorbed by the surface; rather, changes in evapotranspiration lead to changes in the partitioning between sensible and latent heat fluxes, with increased surface temperatures and reduced evaporation when evaporative resistance is increased. Changes in evaporative resistance have the largest impact on surface temperature in wet areas such as the tropics in the offline simulations, with even larger surface temperature responses in the coupled simulations in extratropical regions with both wet soil and relatively dry air, such as southeastern North America and northern Eurasia. Changes in vegetation height modify the aerodynamic resistance of the land surface, and results in a repartitioning of surface energy fluxes between turbulent heat fluxesmostly sensible heat flux - and emitted surface longwave radiation (corresponding to changes in surface temperature). Changes in surface roughness have the largest impact on surface temperatures in warm, dry regions.

When investigating the climate effect of changes in land surface properties, the results are drastically different between offline land-only simulations driven by noninteractive atmospheric data and simulations that account for interactions and feedbacks with the atmosphere. The response of surface temperature to changes in albedo and evaporative resistance are much stronger and have a distinctly different pattern in coupled simulations than offline simulations, with over $50 \%$ of the total temperature change in response to albedo coming from interactions with the atmosphere in over $80 \%$ of land areas. For surface roughness, the pattern and 
magnitude of temperature change are similar, though not identical, between the coupled and offline simulations. The differences in surface energy flux and surface temperature responses to the same change in the land surface between the coupled and offline simulations come from atmospheric feedbacks responding to surface property-driven changes in surface energy fluxes. These atmospheric feedbacks associated with land-atmosphere coupling include changes in atmospheric temperature, humidity, cloud cover (which go on to modify the amount of solar radiation reaching the surface), and circulation. Some of these circulation responses, such as changes in northward heat transport, are large in spatial scale and thus provide a mechanism for surface property changes in one location to impact climate over far-removed land areas.

The inverse relationship presented in this paper describes the change in some land surface property required to produce a change in a given climate variable, for example, the change in albedo required to drive $1 \mathrm{~K}$ of surface warming at some location. This approach provides a framework to analyze the impacts of land management on different aspects of surface climate. This highlights the importance of accounting for local land-atmosphere interaction impacts on climate, and for quantifying the impacts of remote land-use change on the climate of a given region when considering the climate impacts of land management in the future.

The simple land model, SLIM, introduced in this paper provides an ideal framework to assess atmospheric responses to prescribed surface perturbations. It allows us to quantify the climate impacts of individual land surface properties while knowing exactly what is changing on the land surface. We foresee this model being useful in applications such as paleoclimate studies where the exact distribution and behavior of vegetation is unknown, studies where the complexity of a modern land surface model is not needed, studies where unexpected feedbacks with complex land dynamics could interfere with the intended experiments, or studies aimed at understanding the behavior of an Earth system model without complexities in the land surface model.

Acknowledgments. We thank funding support from NSF Grant 1553715 to the University of Washington, NSERC Grant PGSD3-487470-2016, and the Advanced Studies Program visiting graduate student fellowship at the National Center for Atmospheric Research (2016). We thank the three anonymous reviewers for their helpful feedback on this manuscript. We would like to acknowledge high-performance computing support from Cheyenne (doi:10.5065/D6RX99HX) provided by NCAR's Computational and Information Systems Laboratory, sponsored by the National Science Foundation. The SLIM
(Simple Land Interface Model) source code is available on github at https://github.com/marysa/SimpleLand. The data presented in this paper is available through Research Works, the University of Washington Libraries digital repository, at http://hdl.handle.net/1773/43463.

\section{REFERENCES}

Anderson, J. L., and Coauthors, 2004: The new GFDL global atmosphere and land model AM2-LM2: Evaluation with prescribed SST simulations. J. Climate, 17, 4641-4673, https:// doi.org/10.1175/JCLI-3223.1.

Badger, A. M., and P. A. Dirmeyer, 2015: Climate response to Amazon forest replacement by heterogeneous crop cover. Hydrol. Earth Syst. Sci., 19, 4547-4557, https://doi.org/10.5194/ hess-19-4547-2015.

Bailey, D., and Coauthors, 2018: CESM CICE5 Users Guide. Los Alamos National Laboratory, 47 pp., https://media. readthedocs.org/pdf/cesmcice/latest/cesmcice.pdf.

Bala, G., K. Caldeira, M. Wickett, T. J. Phillips, D. B. Lobell, C. Delire, and A. Mirin, 2007: Combined climate and carboncycle effects of large-scale deforestation. Proc. Natl. Acad. Sci. USA, 104, 6550-6555, https://doi.org/10.1073/pnas. 0608998104.

Boisier, J. P., and Coauthors, 2012: Attributing the impacts of landcover changes in temperate regions on surface temperature and heat fluxes to specific causes: Results from the first LUCID set of simulations. J. Geophys. Res., 117, D12116, https://doi.org/10.1029/2011JD017106.

Bonan, G. B., 2002: Ecological Climatology: Concepts and Applications. 1st ed. Cambridge University Press, 678 pp.

_- 2008a: Ecological Climatology: Concepts and Applications. 2nd ed. Cambridge University Press, $550 \mathrm{pp}$.

- 2008b: Forests and climate change: Forcings, feedbacks, and the climate benefits of forests. Science, 320, 1444-1449, https:// doi.org/10.1126/science.1155121.

—, 2015: Ecological Climatology: Concepts and Applications. $3 \mathrm{rd}$ ed. Cambridge University Press, $754 \mathrm{pp}$.

—, D. Pollard, and S. L. Thompson, 1992: Effects of boreal forest vegetation on global climate. Nature, 359, 716-718, https:// doi.org/10.1038/359716a0.

Broccoli, A. J., K. A. Dahl, and R. J. Stouffer, 2006: Response of the ITCZ to Northern Hemisphere cooling. Geophys. Res. Lett., 33, L01702, https://doi.org/10.1029/2005GL024546.

Caldeira, K., G. Bala, and L. Cao, 2013: The science of geoengineering. Annu. Rev. Earth Planet. Sci., 41, 231-256, https:// doi.org/10.1146/annurev-earth-042711-105548.

Canadell, J. G., and M. R. Raupach, 2008: Managing forests for climate change mitigation. Science, 320, 1456-1457, https:// doi.org/10.1126/science.1155458.

Charney, J., 1975: Dynamics of deserts and drought in Sahel. Quart. J. Roy. Meteor. Soc., 101, 193-202, https://doi.org/10.1002/ qj. 49710142802.

, P. H. Stone, and W. J. Quirk, 1975: Drought in the Sahara: A biogeophysical feedback mechanism. Science, 187, 434-435, https://doi.org/10.1126/science.187.4175.434.

—, W. J. Quirk, S.-S.-H. Chow, and J. Kornfield, 1977: A comparative study of the effects of albedo change on drought in semi-arid regions. J. Atmos. Sci., 34, 1366-1385, https://doi.org/ 10.1175/1520-0469(1977)034<1366:ACSOTE>2.0.CO;2.

Chen, G.-S., M. Notaro, Z. Liu, and Y. Liu, 2012: Simulated local and remote biophysical effects of afforestation over the 
southeast United States in boreal summer. J. Climate, 25, 4511-4522, https://doi.org/10.1175/JCLI-D-11-00317.1.

Cheruy, F., J. L. Dufresne, S. Aït Mesbah, J. Y. Grandpeix, and F. Wang, 2017: Role of soil thermal inertia in surface temperature and soil moisture-temperature feedback. J. Adv. Model. Earth Syst., 9, 2906-2919, https://doi.org/10.1002/2017MS001036.

Chiang, J. C. H., and C. M. Bitz, 2005: Influence of high latitude ice cover on the marine Intertropical Convergence Zone. Climate Dyn., 25, 477-496, https://doi.org/10.1007/s00382-005-0040-5.

—, and A. R. Friedman, 2012: Extratropical cooling, interhemispheric thermal gradients, and tropical climate change. Annu. Rev. Earth Planet. Sci., 40, 383-412, https:// doi.org/10.1146/annurev-earth-042711-105545.

Compo, G. P., and Coauthors, 2011: The Twentieth Century Reanalysis Project. Quart. J. Roy. Meteor. Soc., 137, 1-28, https:// doi.org/10.1002/QJ.776.

Davin, E. L., and N. de Noblet-Ducoudré, 2010: Climatic impact of global-scale deforestation: Radiative versus nonradiative processes. J. Climate, 23, 97-112, https://doi.org/10.1175/ 2009JCLI3102.1.

de Noblet-Ducoudré, N., and Coauthors, 2012: Determining robust impacts of land-use-induced land cover changes on surface climate over North America and Eurasia: Results from the first set of LUCID experiments. J. Climate, 25, 3261-3281, https://doi.org/10.1175/JCLI-D-11-00338.1.

Devaraju, N., G. Bala, and A. Modak, 2015: Effects of large-scale deforestation on precipitation in the monsoon regions: $\mathrm{Re}$ mote versus local effects. Proc. Natl. Acad. Sci. USA, 112, 3257-3262, https://doi.org/10.1073/PNAS.1423439112.

, N. de Noblet-Ducoudré, B. Quesada, and G. Bala, 2018: Quantifying the relative importance of direct and indirect biophysical effects of deforestation on surface temperature and teleconnections. J. Climate, 31, 3811-3829, https://doi.org/ 10.1175/JCLI-D-17-0563.1.

Dirmeyer, P. A., 2001: An evaluation of the strength of landatmosphere coupling. J. Hydrometeor., 2, 329-344, https://doi.org/ 10.1175/1525-7541(2001)002<0329:AEOTSO > 2.0.CO;2.

Frierson, D. M. W., and Y.-T. T. Hwang, 2012: Extratropical influence on ITCZ shifts in slab ocean simulations of global warming. J. Climate, 25, 720-733, https://doi.org/10.1175/JCLI-D-11-00116.1.

Garcia, E. S., A. L. S. Swann, J. C. Villegas, D. D. Breshears, D. J. Law, S. R. Saleska, and S. C. Stark, 2016: Synergistic ecoclimate teleconnections from forest loss in different regions structure global ecological responses. PLOS ONE, 11, e0165042, https://doi.org/10.1371/journal.pone.0165042.

Gibbard, S., K. Caldeira, G. Bala, T. J. Phillips, and M. Wickett, 2005: Climate effects of global land cover change. Geophys. Res. Lett., 32, L23705, https://doi.org/10.1029/2005GL024550.

Hunke, E. C., W. H. Lipscomb, A. K. Turner, N. Jeffery, and S. Elliott, 2013: CICE: The Los Alamos Sea Ice Model Documentation and Software User's Manual. LA-CC-06-012, 115 pp.

Hurrell, J. W., and Coauthors, 2013: The Community Earth System Model: A framework for collaborative research. Bull. Amer. Meteor. Soc., 94, 1339-1360, https://doi.org/10.1175/BAMS-D-12-00121.1.

Kang, S. M., I. M. Held, D. M. W. Frierson, and M. Zhao, 2008: The response of the ITCZ to extratropical thermal forcing: Idealized slab-ocean experiments with a GCM. J. Climate, 21, 35213532, https://doi.org/10.1175/2007JCLI2146.1.

Kooperman, G. J., Y. Chen, F. M. Hoffman, C. D. Koven, K. Lindsay, M. S. Pritchard, A. L. Swann, and J. T. Randerson, 2018: Forest response to rising $\mathrm{CO}_{2}$ drives zonally asymmetric rainfall change over tropical land. Nat. Climate Change, $\mathbf{8}$, 434-440, https://doi.org/10.1038/s41558-018-0144-7.
Laguë, M. M., and A. L. S. Swann, 2016: Progressive midlatitude afforestation: Impacts on clouds, global energy transport, and precipitation. J. Climate, 29, 5561-5573, https://doi.org/10. 1175/JCLI-D-15-0748.1.

Lawrence, D., R. Fisher, C. Koven, K. Oleson, S. Swenson, and M. Vertenstein, 2018: Technical description of version 5.0 of the Community Land Model (CLM). 329 pp., http://www.cesm. ucar.edu/models/cesm2/land/CLM50_Tech_Note.pdf.

Lee, X., and Coauthors, 2011: Observed increase in local cooling effect of deforestation at higher latitudes. Nature, 479, 384387, https://doi.org/10.1038/nature10588.

Manabe, S., and K. Bryan, 1969: Climate calculations with a combined ocean-atmosphere model. J. Atmos. Sci., 26, 786-789, https:// doi.org/10.1175/1520-0469(1969)026<0786:CCWACO > 2.0.CO;2.

Medvigy, D., R. L. Walko, M. J. Otte, and R. Avissar, 2013: Simulated changes in northwest U.S. climate in response to Amazon deforestation. J. Climate, 26, 9115-9136, https://doi.org/ 10.1175/JCLI-D-12-00775.1.

Milly, P. C. D., and B. Shmakin, 2002: Global modeling of land water and energy balances. Part I: The Land Dynamics (LaD) model. J. Hydrometeor., 3, 283-299, https://doi.org/10.1175/ 1525-7541(2002)003<0283:GMOLWA > 2.0.CO;2

Neale, R. B., and Coauthors, 2012: Description of the NCAR Community Atmosphere Model (CAM 5.0). NCAR Tech. Note NCAR/TN-486+STR, 274 pp., www.cesm.ucar.edu/ models/cesm1.0/cam/docs/description/cam5_desc.pdf.

Park, S., and C. S. Bretherton, 2009: The University of Washington shallow convection and moist turbulence schemes and their impact on climate simulations with the Community Atmosphere Model. J. Climate, 22, 3449-3469, https://doi.org/10. 1175/2008JCLI2557.1.

Pitman, A. J., and Coauthors, 2009: Uncertainties in climate responses to past land cover change: First results from the LUCID intercomparison study. Geophys. Res. Lett., 36, L14814, https://doi.org/10.1029/2009GL039076.

Shukla, J., and Y. Mintz, 1982: Influence of land-surface evapotranspiration on the Earth's climate. Science, 215, 1498-1501, https://doi.org/10.1126/science.215.4539.1498.

Sud, Y. C., J. Shukla, and Y. Mintz, 1988: Influence of land surface roughness on atmospheric circulation and precipitation: A sensitivity study with a general circulation model. J. Appl. Meteor., 27, 1036-1054, https://doi.org/10.1175/1520-0450(1988) 027<1036:IOLSRO > 2.0.CO;2.

Swann, A. L. S., I. Y. Fung, S. Levis, G. B. Bonan, and S. C. Doney, 2010: Changes in Arctic vegetation amplify high-latitude warming through the greenhouse effect. Proc. Natl. Acad. Sci. USA, 107, 1295-1300, https://doi.org/10.1073/pnas.0913846107. , — , and J. C. H. Chiang, 2012: Mid-latitude afforestation shifts general circulation and tropical precipitation. Proc. Natl. Acad. Sci. USA, 109, 712-716, https://doi.org/10.1073/ pnas. 1116706108 .

_ , and Coauthors, 2018: Continental-scale consequences of tree die-offs in North America: Identifying where forest loss matters most. Environ. Res. Lett., 13, 055014, https://doi.org/ 10.1088/1748-9326/aaba0f.

Vargas Zeppetello, L. R., A. Donohoe, and D. S. Battisti, 2019: Does surface temperature respond to or determine downwelling longwave radiation? Geophys. Res. Lett., 46, 27812789, https://doi.org/10.1029/2019GL082220.

Zhang, X., S. Chen, M. Liu, D. Pei, and H. Sun, 2005: Improved water use efficiency associated with cultivars and agronomic management in the North China Plain. Agron. J., 97, 783-790, https://doi.org/10.2134/agronj2004.0194. 